OPEN ACCESS

Edited by:

Vittorio Capozzi,

University of Foggia, Italy

Reviewed by:

Abhinav Upadhyay,

University of Connecticut,

United States

Issmat Kassem,

American University of Beirut,

Lebanon

*Correspondence: Steven C. Ricke

sricke@uark.edu

Specialty section:

This article was submitted to

Food Microbiology,

a section of the journal

Frontiers in Microbiology

Received: 30 January 2019

Accepted: 26 April 2019

Published: 14 May 2019

Citation:

Micciche A, Rothrock MJ Jr, Yang Y and Ricke SC (2019) Essential

Oils as an Intervention Strategy to Reduce Campylobacter in Poultry

Production: A Review.

Front. Microbiol. 10:1058

doi: 10.3389/fmicb.2019.01058

\section{Essential Oils as an Intervention Strategy to Reduce Campylobacter in Poultry Production: A Review}

\author{
Andrew Micciche ${ }^{1}$, Michael J. Rothrock Jr. ${ }^{2}$, Yichao Yang ${ }^{3}$ and Steven C. Ricke ${ }^{1 *}$ \\ ${ }^{1}$ Center of Food Safety, Department of Food Science, University of Arkansas, Fayetteville, AR, United States, ${ }^{2}$ United States \\ Department of Agriculture, Agricultural Research Service, Athens, GA, United States, ${ }^{3}$ Department of Poultry Science, \\ University of Arkansas, Fayetteville, AR, United States
}

Campylobacter is a major foodborne pathogen and can be acquired through consumption of poultry products. With 1.3 million United States cases a year, the high prevalence of Campylobacter within the poultry gastrointestinal tract is a public health concern and thus a target for the development of intervention strategies. Increasing demand for antibiotic-free products has led to the promotion of various alternative pathogen control measures both at the farm and processing level. One such measure includes utilizing essential oils in both pre- and post-harvest settings. Essential oils are derived from plant-based extracts, and there are currently over 300 commercially available compounds. They have been proposed to control Campylobacter in the gastrointestinal tract of broilers. When used in concentrations low enough to not influence sensory characteristics, essential oils have also been proposed to decrease bacterial contamination of the poultry product during processing. This review explores the use of essential oils, particularly thymol, carvacrol, and cinnamaldehyde, and their role in reducing Campylobacter concentrations both pre- and post-harvest. This review also details the suggested mechanisms of action of essential oils on Campylobacter.

Keywords: Campylobacter, poultry, essential oils, oregano, thymol, carvacrol, cinnamaldehyde

\section{INTRODUCTION}

Campylobacter is a leading cause of human gastroenteritis in the United States and worldwide (Corcionivoschi et al., 2012; Sibanda et al., 2018). In the United States alone, the Centers for Disease Controls and Prevention (CDC) estimates an annual 1.3 million cases occurring per year (Centers for Disease Control and Prevention [CDC], 2018). From 1999 to 2008, Campylobacter was estimated to cause an annual 8,463 hospitalizations and 76 deaths in the United States, along with an annual \$1.7 billion financial cost to the United States (Batz et al., 2012). In 2015, of the 4,598 hospitalizations caused by foodborne disease 1,087 were the result of Campylobacter (Centers for Disease Control and Prevention [CDC], 2017a). This burden on public health was second only to Salmonella when considering bacterial infections (Batz et al., 2012; Scallan et al., 2015). When aggregating the loss of life and health due to illness, Scallan et al. (2015) determined that annually, Campylobacter caused 22,500 disability-adjusted life years (DALY). Campylobacter was ranked $3^{\text {rd }}$ as the leading impact of public health due to foodborne illness behind non-typhoidal Salmonella (32,900 DALY) and Toxoplasma (32,700 DALY). A systematic analysis from 1990 to 2013 identified Campylobacter as the fourth leading cause of diarrheal disease behind rotavirus, typhoid fever, 
and cryptosporidiosis (Murray et al., 2015). According to the World Health Organization (WHO), diarrheal diseases, viewed as a whole, cause an estimated 550 million illness each year resulting in the annual death of approximately half a million infants under the age of two (World Health Organization [WHO], 2013).

In a population-based study on patients with diarrheal illness induced by Campylobacter, over 95\% of the 1,316 cases were caused by Campylobacter jejuni (Friedman et al., 2004). This species, along with pathogen Campylobacter coli, have been found in the gastrointestinal tract (GIT) of poultry (Wang et al., 2002; European Food Safety Authority [EFSA], 2010; Centers for Disease Control and Prevention [CDC], 2017b). Broilers and layer flocks have consistently been shown to contain Campylobacter prevalences greater than 70\% (Corry and Atabay, 2001; Stern et al., 2001; Ansari-Lari et al., 2011; Sahin et al., 2015). Schets et al. (2017) found that 97\% of layer and 93\% of broiler flocks tested positive for Campylobacter. Across eight flocks in the Netherlands, 55 cecal samples were taken and found that C. jejuni was the Campylobacter isolate for $100 \%$ of cecal broiler samples where in layer hens $52 \%$ were C. coli, $40 \%$ were C. jejuni (40\%) and $7 \%$ were C. lari. Identical sequence types were found in the soil, sediment, and surface water which indicates potential contamination of the bird through environmental means. Through contamination of the poultry carcass, Campylobacter can cause foodborne illness and has been the etiological agent in outbreaks caused by poultry products (Nauta et al., 2009; Geissler and Powers, 2011). Therefore there is a continued urgency to implement pre- and post-harvest technologies to prevent Campylobacter contamination at all stages of poultry production.

With the rise of multidrug-resistant bacteria, consumer preference for antibiotic-free chicken, and government regulations such as the European Union's 2006 ban of antibiotics, alternative antimicrobials have become necessary (Cervantes, 2015; Johnson, 2015; Shin et al., 2015). One alternative to conventionally implemented pre- and post-harvest antimicrobial strategies is the use of essential oils (EOs) (Tiihonen et al., 2010; Amerah et al., 2012; Calo et al., 2015; O’Bryan et al., 2015; Thibodeau et al., 2015; Micciche et al., 2018b). The EOs industry had a United States market share of $\$ 6.6$ billion in 2016 , a $286 \%$ increase from the 2004 market share of $\$ 2.3$ billion (Zviely, 2004; Grand View Research, 2018). They are often used as flavoring agents in food products and perfumes, embalmment, anti-inflammatory and anesthesia remedies (Burt, 2004; Bakkali et al., 2008). Some EOs, such as eugenol, have been reported to have a preventative effect against cancer (Burt, 2004; Tsuneki et al., 2005; Bakkali et al., 2008). Plant-based EOs such as eugenol, thymol, carvacrol, and cinnamaldehyde have been examined and screened for their antimicrobial properties against a number of pathogens including Campylobacter (Friedman et al., 2002; Chouliara et al., 2007; Thibodeau et al., 2015; Kelly et al., 2017; Upadhyay et al., 2017). They are also commercially attractive as alternative antimicrobials, because they are considered acceptable for organic and non-conventional applications (Micciche et al., 2018b; National Organic Program, 2018). They may be useful not only in preventing human health-related diseases but in improving the performance of the bird
(Alcicek et al., 2004; Hernandez et al., 2004; Diaz-Sanchez et al., 2015; National Organic Program, 2018). As such, the objective of this review was to discuss EOs as an intervention approach for limiting Campylobacter contamination in the poultry industry pre- and post-harvest. By investigating the metabolic activity of Campylobacter, a greater understanding of the mechanistic effects of EOs may be elucidated for more optimal application approaches in the future.

\section{Campylobacter CHARACTERISTICS AND METABOLISM}

Campylobacter belongs to family Campylobacteraceae, which also includes Arcobacter and Helicobacter (Fitzgerald and Nachamkin, 2011). They are non-sporulating Gram-negative microorganisms, with an s-shape and cell dimensions between 0.5 and $5 \mu \mathrm{m}$ and ranging in width from 0.2 to $0.9 \mu \mathrm{m}$ (Vandamme et al., 2006). A single polar flagellum is found in 20 of the 22 species with the exception being the non-motile C. gracilis and C. showae that possess multiple flagella (Debruyne et al., 2008; Facciolà et al., 2017). Campylobacter spp. are microaerophilic and grow optimally in a gas composition of $5 \% \mathrm{O}_{2}, 10 \% \mathrm{CO}_{2}$, and $85 \% \mathrm{~N}_{2}, \mathrm{pH}$ of 6.5 to 7.57 and from 37 to $42^{\circ} \mathrm{C}$ (Garénaux et al., 2008; Davis and DiRita, 2017; Facciolà et al., 2017). Campylobacter will not grow at temperatures below $30^{\circ} \mathrm{C}$, due to an absence of a cold shock protein gene, or with a water activity below 0.987, which is necessary to maintain turgor pressure (Hazeleger et al., 1998; De Cesare et al., 2003; Wallace, 2003; Levin, 2007; Facciolà et al., 2017). Cold shock proteins range from 65 to 75 amino acids serve as nucleic acid chaperones that prevent mRNA secondary structures from forming which enable efficient transcription and translation (Phadtare and Severinov, 2010; Keto-Timonen et al., 2016). Interestingly, despite the lack of a cold shock protein, biofilms of C. jejuni have been found to form and persist in $13^{\circ} \mathrm{C}$ conditions and formed biofilms with the largest surface area compared to 20,37, and $42^{\circ} \mathrm{C}$ (Sanders et al., 2008). Attachment of planktonic cells to the biofilms was not significantly impacted by temperature (Sanders et al., 2008).

Compared to other foodborne pathogens occupying the poultry GIT, Campylobacter possesses a metabolism that is somewhat different and thus may be a challenge for some intervention strategies. Campylobacter spp. do not utilize the traditional glycolysis pathway, instead favoring amino acids such as aspartate, glutamate, serine, and proline for their cellular respiration pathways (Stahl et al., 2012). The traditional glycolytic pathway is incomplete as genes encoding glucokinase and 6-phosphofructokinase are absent (Parkhill et al., 2000). Furthermore, despite a complete tricarboxylic acid cycle (TCA), gluconeogenesis from glucose-6-phosphate to glucose is not observed, and the genes necessary for encoding the proteins associated with the pathway are absent (Parkhill et al., 2000; Velayudhan and Kelly, 2002). Some of the gluconeogenesis and glycolysis genes and respective proteins are present which has led to the hypothesis that $C$. jejuni can catabolize intermediary molecules (Stahl et al., 2012). For instance, Hofreuter et al. (2006) 
suggested that the presence of a glycerol-3-phosphate transporter (GlpT) in C. jejuni 81176 could be indicative of the breakdown of glycerol-3-phosphate to generate pyruvate and potential further breakdown through the TCA cycle. Additionally, the non-oxidative portion of the pentose pathway shunt (transaldolase, transketolase, ribulose-3-phosphate epimerase, and ribose-5-phosphate isomerase) is suggested to have the ability to metabolize pentose sugars (Line et al., 2010).

Two studies independently identified novel l-fucose pathways with a l-fucose permease that is homologous to the one characterized in E. coli (Dang et al., 2010; Muraoka and Zhang, 2010; Stahl et al., 2011). Fucose is a component of eukaryotic glycoproteins and is found in mucin (Allen and Griffiths, 2001; Robbe et al., 2004). Campylobacter jejuni utilizes fucose as a chemoattractant for mucin attachment (Hugdahl et al., 1988; Tu et al., 2008; Gangaiah et al., 2010; Kassem et al., 2013). While fucose uptake was phenotypically observed in C. jejuni strain NCTC 11168 (isolated from human feces), it was not detected in strains 81116 and 81176 (Muraoka and Zhang, 2010). This is due to the presence of a genomic island cj0480c-cj0490, which has been linked to an increase in virulence (Parker et al., 2006). Stahl et al. (2011) noted that this metabolic pathway improved colonization of the piglet model for human disease indicating its importance in human-associated pathogenesis. Moreover, when the l-fucose pathway genes were mutated, C. jejuni was still able to colonize the ceca of chickens but was outcompeted in a co-colonization experiment by the wild-type strain (Muraoka and Zhang, 2010). Despite the presence of this metabolic pathway, Campylobacter is largely asaccharolytic and relies primarily on amino acids and organic acids for its energy and carbon needs (Lin et al., 2009; Stahl et al., 2012; Kassem et al., 2013; Kelly et al., 2017).

Amino acids utilized by Campylobacter as carbon and energy sources include asparagine, glutamine, serine, aspartate, and proline (Wright et al., 2009). Campylobacter jejuni will preferentially utilize serine, aspartate, asparagine, and glutamate (Guccione et al., 2008; Wright et al., 2009; Stahl et al., 2012). Parsons (1984) determined the most common amino acids within the ceca of leghorn hens through ion-exchange chromatography. Serine ranked $4^{\text {th }}(92.2 \mathrm{mmol} / \mathrm{mol}$ ceca content), aspartate ranked $2^{\text {nd }}(109.9 \mathrm{mmol} / \mathrm{mol}$ ceca content), and glutamate ranked $1^{\text {st }}(137.5 \mathrm{mmol} / \mathrm{mol}$ ceca content $)$ as the most concentrated amino acids within the ceca. Asparagine, glutamine, glycine, cysteine, and tryptophan concentrations were not reported. While these concentrations will vary depending on diet, GIT microbial population, and bird type, the data provides insight into why amino acid metabolism of C. jejuni could play an essential role in its ecological niche within the poultry GIT (Ravindran and Bryden, 1999; Stahl et al., 2012). Whereas other species must rely on carbohydrate fermentation, the plentiful concentration of amino acids in the poultry ceca, due to protein-rich diets, allows Campylobacter to thrive (Józefiak et al., 2004; Vegge et al., 2009; Hermans et al., 2012).

Not all poultry dietary components contribute directly to the nutrition of the bird but may still interact with the GIT microbial population including resident foodborne pathogens. For example, there are primary plant compounds and secondary plant metabolites present in the poultry GIT that may not necessarily serve directly as nutrients but can still nutritionally influence bird performance (Smithard, 2002). While some fiber components, particularly lignin, are generally considered indigestible in the avian GIT, they can still impact GIT microbial composition, alter fermentation patterns, and influence metabolite absorption (Ricke et al., 1982, 2013; Jung and Fahey, 1983; van der Aar et al., 1983; Dunkley et al., 2007; Baurhoo et al., 2008; Sima et al., 2018). These high fiber sources have also been shown to limit the establishment of foodborne pathogens such as Salmonella Enteritidis in laying hens when serving as the primary dietary source in laying hens (Ricke, 2003; Woodward et al., 2005; Ricke et al., 2013). Plants also contain phenolic monomers (Jung and Fahey, 1983). Phenolic monomers can not only cross-link carbohydrates with lignin in the plant, decreasing fiber degradation in the GIT, but in their free form can be antimicrobial to aerobic and anaerobic bacteria (Zemek et al., 1979; Jung and Fahey, 1983).

Aromatic compounds can also be modified anaerobically (Tschech and Schink, 1985; Netzer et al., 2016). Often phenolic compounds such as chlorophenol and chlorobenzoate can be utilized as electron sinks, resulting in their reduction and modification within the lower GIT (Häggblom et al., 1993; Frazer, 1994). While Campylobacter has been shown to utilize some aromatic compounds such as resorcinol and $\beta$ or $\gamma$-resorcylate, this was only shown in the presence of Clostridium spp. (Tschech and Schink, 1985; Evans and Fuchs, 1988). However, other aromatic compounds can be utilized as energy sources by some bacteria (Overhage et al., 2006). MetaCyc identifies five complete aromatic degradation pathways present in E. coli including cinnamate, phenylethylamine, nitroaromatic, and phenols (version 22.5; BioCyc; Menlo Park, CA, United States) (Caspi et al., 2015). Chlorobenzene, paraoxon, parathion, and shikimate degradation pathways have been identified in L. monocytogenes and degradation of $p$-cymene, along with other aromatic compounds, have been characterized in Pseudomonas spp. In Campylobacter, only the catechol degradation pathway has been detected. Numerous biodegradation enzymes have been elucidated in E. coli; for instance, eugenol has been shown to be degraded to ferulic acid by the vaoA gene-encoded enzymes (Díaz et al., 2001; Overhage et al., 2003, 2006). However, only resorcinol, protocatechuate, and phloroglucionol degradation enzymes are known to occur in Campylobacter (Evans and Fuchs, 1988; Villemur, 1995). Given the limited metabolic capacity of Campylobacter for modification, it would be intuitive that aromatic compounds that exhibit antimicrobial properties could effectively reduce Campylobacter populations in poultry production. This is important since aromatic compounds are one of the constituents present in phytobiotics.

\section{PHYTOBIOTICS}

Phytobiotics are plant-based compounds or extracts that have been suggested for use in commercial, and possibly organic, poultry production (Windisch and Kroismayr, 2007; Bakkali et al., 2008; Diaz-Sanchez et al., 2015; Micciche et al., 2018b). 
Most phytobiotics are Generally Recognized As Safe (GRAS) by the U.S Food and Drug Administration [FDA], 2018 and are less toxic and typically more residual-free compared to synthetic antibiotics (Diaz-Sanchez et al., 2015; U.S Food and Drug Administration [FDA], 2018). Botanicals, a subset of phytobiotics, are leaves, roots, bark, or other parts of a plant, and the terminology is often used interchangeably with phytobiotics (Windisch and Kroismayr, 2006; Mohammadhosseini et al., 2017). Other types of phytobiotics include herbs, which are derived from flowering non-persistent plants, oleoresins which are non-aqueous extracts such as balsam, and EOs (Prior and Cao, 2000). In this review, the focus will primarily be on the activity of EOs, but other phytobiotic compounds such as herbs will also be mentioned.

Essential oils, also known as volatile or ethereal oils, are oily plant-based liquids that possess aromatic properties (Burt, 2004; Hardin et al., 2010). The term "essential oils" was first coined by Paracelsus von Hohenheim in the $16^{\text {th }}$ century (Guenther(ed.), 1948). The term 'essential' relates to the effective element in a medical preparation of the drug and is therefore loosely defined (Oyen and Dung, 1999). Currently, there are over 3,000 known EOs with approximately 300 being commercially relevant (Bakkali et al., 2008; Diaz-Sanchez et al., 2015). They include oils such as turpentine, eugenol, and cinnamaldehyde, and can be derived from other botanical compounds and herbs such as thyme, oregano, rosemary, and lemon (Burt, 2004; Fisher and Phillips, 2008; Diaz-Sanchez et al., 2015). Essential oils are extracted from their corresponding plants by steam distillation, hydrodistillation, or solvent extraction which all can create a concentrate of aromatic and volatile compounds including terpenoids and phenylpropanoids (Nakatsu et al., 2000; Hardin et al., 2010; Raut and Karuppayil, 2014). The concentrations of the 'essential' compounds in EOs vary wildly and are not typically defined (Lee et al., 2004a; Benavides et al., 2012).

\section{NON-ANTIMICROBIAL EFFECTS OF EOS IN POULTRY}

Essential oils have a wide range of applications including turpentine for paint mixing or linalool and linalyl acetate that are used as alternative sleep aides (Buchbauer et al., 1991; Burt, 2004). Many are incorporated as ingredients for their palatable tastes and smells in foods and aromatic sprays (Franz et al., 2010). Oregano, thyme, and cinnamon are well-known flavor enhancers (Khan and Abourashed, 2011; Wang et al., 2013). Bergamon is used for its aromatic properties of Earl Gray Tea, while synthetic based citrus oils are an ingredient in soft drinks (Fabricant, 2008; Gonzalez-Molina et al., 2009; Callaway et al., 2011). While 32.9\% of EOs are applied in the food and beverage industry, the second largest application of EOs in 2015 was for spa or relaxation purposes (30.84\%) (Grand View Research, 2018).

In poultry, EOs have been utilized in preharvest management settings for non-pathogen related benefits (Diaz-Sanchez et al., 2015). Digestibility of poultry feed has been shown to be improved by the addition of EOs (Williams and Losa, 2001). CRINA $^{\circledR}$ (Akzo Nobel, Crina S.A, Switzerland) is a commercial blend of EOs containing thymol, eugenol, and piperine. Broilers fed $50 \mathrm{mg} / \mathrm{kg}$ of $\mathrm{CRINA}^{\circledR}$, exhibited improved activity of total amylase, trypsin, and maltase of $40 \mathrm{kU} /$ pancreas, $63 \mathrm{U} /$ pancreas, and $12.6 \mu \mathrm{M} / \mathrm{g}$ mucosa respectively, compared to the control group activity of $29 \mathrm{kU} /$ pancreas, $42 \mathrm{U} /$ pancreas, and $10.6 \mu \mathrm{M} / \mathrm{g}$ mucosa, respectively (Jang et al., 2004, 2007). This effect was not observed; however, when $0.1 \%$ of lactate was also introduced into the diet (Jang et al., 2004). The use of $200 \mathrm{ppm}$ of a blend of oregano, cinnamon, and pepper improved fecal digestibility of dry matter (Hernandez et al., 2004). Ileal absorption levels of amino acids such as threonine, serine, asparagine, phenylalanine, histidine, and lysine were positively improved by 7.8 and $8.8 \%$ by the addition of 150 and $300 \mathrm{ppm}$ of a plant extract containing capsaicin, carvacrol, and cinnamaldehyde (Jamroz et al., 2003).

Amino acid absorption studies have also been performed using rat intestines. A catheter was attached to both ends of a sector of the jejunum of anesthetized rats (Kreydiyyeh et al., 2000). In the treatment groups, the jejuna were preincubated with $1000 \mathrm{ppm}$ cinnamaldehyde or $850 \mathrm{ppm}$ of eugenol or a saline control. Alanine was then fed through the jejuna, and it was observed that after $40 \mathrm{~min}$ the jejuna preincubated with cinnamaldehyde and eugenol absorbed 22 to $25 \mathrm{nmol}$ of alanine compared to $60 \mathrm{nmol}$ in the control. This suggests reduced nutrient absorption (Kreydiyyeh et al., 2000; Lee et al., 2004a). However, conclusions drawn from this study may be difficult to apply to production animals due to the high concentrations necessary in the feed to result in similar concentrations in the GIT as utilized in Kreydiyyeh et al. (2000). Lee et al. (2003) observed that $100 \mathrm{ppm}$ of thymol or cinnamaldehyde exhibited no significant effect on pancreatic digestive enzyme activity at day 21 or day 40 within female broilers (Lee et al., 2004a). This study shows that thymol alone is unable to impact pancreatic digestive enzymes within poultry and a combination of multiple EOs, such as in Jang et al. (2004, 2007), may be necessary to impact digestibility responses in broilers. However, it may be specific combinations of EOs that impact digestibility and nutrient absorption.

Improvements in nutrient absorption and digestibility can result in improved growth rates within broilers (Gous, 2010). Feed conversion ratio (FCR), the ratio between feed intake and average weight gain, is one of the more commonly used metrics to determine if a feed additive is beneficial to commercial livestock production (Leenstra, 1986). Several studies have reported no improvement in growth rate or FCR when diets have been supplemented with EOs (Lee et al., 2003; Jang et al., 2004, 2007). However, FCR and body weight gain (BWG) improvements have been observed in other studies that utilized EOs (Denli et al., 2004; Cabuk et al., 2006; Basmacioğlu Malayoğlu et al., 2010). Cabuk et al. (2006) demonstrated that 24 or $48 \mathrm{mg} / \mathrm{kg}$ of Heryumix $^{\mathrm{TM}}$ significantly improved FCR on days 21 to 1.53 and 1.56 compared to the control at 1.62 . On day 42 , compared to the control at 1.87, the FCR was also improved to 1.80 and 1.77 with 24 or $48 \mathrm{mg} / \mathrm{kg}$ of Heryumix ${ }^{\mathrm{TM}}$ (Cabuk et al., 2006). Heryumix ${ }^{\mathrm{TM}}$ is composed of oregano, laurel leaf, sage, myrtle, fennel, and citrus peel extracts (Herba Gida Maddeleri; Seferihisar, Turkey). Denli et al. (2004) observed similar improvements in quail when their diet was supplemented with $60 \mathrm{mg} / \mathrm{kg}$ of thyme or black seed oil. 
This discrepancy may be due to certain variables including bird type, feed composition, and EO type. The intestinal mucosa and GIT microbiome composition of birds vary depending on the species and age of the bird (Zoetendal et al., 2004; Stanley et al., 2014). While the phyla Bacteroidetes and Firmicutes are dominant within quail and broiler chicken cecal microbiomes, the represented genera are different (Oakley et al., 2014; Liu et al., 2015). Over 117 different genera were identified by Wei et al. (2013) in broiler chicken ceca. The quail microbiome, however, is not as taxonomically rich at the genus level with only 32 genera being detected by Wilkinson et al. (2016). Furthermore, while the top five most dominant genera based on taxa analyses were Lactobacillus, Rumiunoccocus, Clostridium, Bacteroides, Faecalibacterium in the chicken cecal microbiome, the quail ceca microbiome was dominated by Bacteroides, Ruminococcus, Faecalibacterium, Enterococcus, and Clostridium (Wei et al., 2013; Wilkinson et al., 2016). These microbiome differences along with unknown host-species interactions should be considered when evaluating and comparing the effectiveness of any particular feed amendment across species (Koutsos and Arias, 2006).

Additionally, the feed may play a major role in how EOs improve FCR. As elucidated in Jamroz et al. (2003), EOs can impact the absorption of amino acids and potentially other nutrients in the ileum. As a consequence, the FCR should be improved in birds on typical commercial diets amended with EOs. Furthermore, improved absorption of amino acids could conceivably also allow for the use of non-conventional diets that contain less protein. In-depth studies employing not only commercial bird performance measurements but intestinal pathway and tissue profiling to screen and compare feed composition and EO blend combinations would be necessary to address this hypothesis.

Finally, while terpenoids are the main constituents of EOs, their chemistry can vary widely (Jager, 2010). For instance, carvacrol is a monoterpene alcohol and, in rats, its aliphatic group readily undergo aromatic hydroxylation while its alcohol group undergoes carboxylation (Jahrmann, 2007; Jager, 2010). Thymol on the other hand forms derivatives of benzyl alcohol and 2-phenylpropanol when reduced (Austgulen et al., 1987). When carvacrol was fed to rats, their excreted urine contained more of 2-(3-Hydroxy-4-methylphenyl)propan-2-ol then carvacrol but when thyme was fed to rats it was in the highest concentration out of its five derivates (Austgulen et al., 1987). This suggests, in rats, that carvacrol undergoes chemical interactions and is metabolized more than thymol. This functional difference between EO metabolism, along with the importance of bird type and feed composition, may in part explain the variation in EOs benefit to broiler nutrition.

Although there is variation in EOs benefit to poultry growth, the antioxidant activity of many EOs is well-known (Baratta et al., 1998; Ruberto et al., 2000; Martucci et al., 2015). Rosemary oil, thymol, carvacrol, oregano, ginger, and coriander all possess antioxidant activity (Wei and Shibamoto, 2007). An oxidation deterioration test involving the application of EOs to lard indicated that $0.20 \%$ oregano possessed the most antioxidant capacity followed by thyme, dittany, marjoram, spearmint, then lavender (Economou et al., 1991). Economou et al. (1991) also found that combinations of thyme and marjoram and thyme and spearmint EOs also had potential synergistic properties in protecting lard from oxidation. These properties benefit bird health and can be marketable if EOs are used on the finished product (Lee et al., 2004b; Diaz-Sanchez et al., 2015).

Additionally, the sensory characteristics of EOs mean that they can enhance the sensory characteristics of the final products if used in the appropriate concentrations. The addition of $300 \mathrm{mg} / \mathrm{kg}$ of oregano, garlic, or an equal combination in the diets was shown to significantly improve the flavor of frozen chicken breasts up to 60 days (Kirkpinar et al., 2014). Birds fed the EOs were processed, and the breasts were stored at $-25^{\circ} \mathrm{C}$ for sensory analysis. Overall flavor evaluated on days 1, 15, and 30 indicated that all EOs treatments scored significantly higher than the control. Overall acceptability scores of breast meat indicated that only garlic resulted in a more palatable final product on days 1,15 , and 30. Overall acceptability scores were based on flavor, appearance, and tenderness. Days 45 and 60 scores were not analyzed statistically due to spoilage. On organic seabass filets, the addition of $0.2 \%$ thyme oil improved the sensory characteristics (Kostaki et al., 2009). A panel of seven judges evaluated the filets on nine days within a 21-day storage trial where the filets were held at $-30^{\circ} \mathrm{C}$. While the control group reached the acceptability limit on taste in 6 days the addition of $0.2 \%$ thyme improved the sensory characteristics scores extending shelf life by 2 days. When the filets were placed in modified atmospheric packaging (MAP) $\left(60 \% \mathrm{CO}_{2} ; 30 \% \mathrm{~N}_{2} ; 10 \% \mathrm{O}_{2}\right)$, sensory characteristics were improved to allow for a shelf life of 14 days. When thyme oil was added to the MAP, shelf life was extended by 3 days. Despite these potential benefits, their antimicrobial activities might be some of their more important attributes to commercial poultry production.

\section{ANTIMICROBIAL MECHANISMS OF ESSENTIAL OILS}

\section{Indirect Antimicrobial Mechanisms}

There are indirect characteristics associated with the presence of EOs that may play a role in reducing Campylobacter and other pathogen loads on the final poultry meat product. While no definitive mechanism has been elucidated, there have been several potential antimicrobial outcomes that may indirectly impact Campylobacter. For instance, the improved ileal absorption of amino acids within broilers, as demonstrated by Jamroz et al. (2003), may limit a required nutrient source for Campylobacter in the ceca (Velayudhan et al., 2004). Improvement of the immune response may also impact pathogen concentrations (Diaz-Sanchez et al., 2015). Layer hens exhibited improved antibody titer levels to Newcastle disease and infectious bursal disease when their diets were supplemented with Heryumix ${ }^{\mathrm{TM}}$ (Özek et al., 2011). In another study with Heryumix ${ }^{\mathrm{TM}}$, the humoral immune response of layer hens in heat stress was not stimulated (Bozkurt et al., 2012). Basmacioğlu Malayoğlu et al. (2010), noted that broilers fed 0,250 , or $500 \mathrm{mg} / \mathrm{kg}$ of oregano exhibited IgG concentrations of 27.42, 30.50, and $39.41 \mathrm{mg} / \mathrm{dL}$, respectively. The $\operatorname{IgM}$ concentrations were 7.91, 9.58, and 
$11.71 \mathrm{mg} / \mathrm{dL}$, respectively (Basmacioğlu Malayoğlu et al., 2010). However, while these concentrations of antibodies were higher, they were not statistically significant $(P>0.05)$ (Basmacioğlu Malayoğlu et al., 2010). As such, further research should be conducted to elucidate the mechanism(s) of EOs on the poultry immune system. Understanding how EOs improve the immune system of poultry may be important because Campylobacter colonization may elicit an immune response, and therefore there is potential to reduce Campylobacter concentrations through immune system modulation (Connerton et al., 2018). Essential oils may also interact with Campylobacter populations directly.

\section{Direct Antimicrobial Mechanisms}

Much of the mechanisms associated with antimicrobial activities of EOs have been elucidated from microorganisms other than Campylobacter, and thus assumptions regarding Campylobacter must be inferred to some extent. General antimicrobial mechanisms associated with EOs have been extensively described previously by O'Bryan et al. (2015) and will be discussed briefly in the current review with specific emphasis on Campylobacter where applicable. Essential oils have been shown to alter proteomes and cell morphology of pathogenic bacteria (Nazzaro et al., 2013; O'Bryan et al., 2015). Significant morphological differences in cell shape have been observed when EOs such as mint, thymol, and cinnamaldehyde have been applied to bacteria (Kwon et al., 2003; Kalchayanand et al., 2004; Hajlaoui et al., 2009). For instance, the use of cinnamaldehyde on Bacillus cereus inhibited cell division resulting in elongated filamentous cells that were clumped together with incomplete septa (Kwon et al., 2003). After $1 \mathrm{~h}$, almost all cells were in filamentous chains with no clear septas. Salmonella enterica serovar Thompson grown in the presence of a sub-lethal concentration of thymol (0.01\%) demonstrated an altered proteomic profile compared to the control, which included downregulation of binding and chemotaxis proteins, but resulted in upregulation of other outer membrane proteins (Di Pasqua et al., 2010). In-depth analysis using 2-D PAGE, followed by MALDI-TOF, revealed that GroEL and DnaK were upregulated in the presence of thymol. GroEL, along with GroES, as well as DnaK, along with DnaJ, prevents misfolding and proper indiscriminate assembly of polypeptides under stress conditions within the cytoplasm (Fenton and Horwich, 1997; Motojima, 2015). Changes in regulation were detected by spot detection, and the relative size of the GroEL spot was 0.109 units in the control compared to a spot size of 1.044 units. The DnaK spot was not detected in the control but exhibited a size of 0.267 in the treatment with thymol. Other downregulated proteins include $\mathrm{CheW}$, which is involved in transferring sensory signals from chemoreceptors to flagellar motor proteins, and thioredoxin docking proteins (Trx1). The spot size of CheW was 0.153 units and was not detected in the thymol treated cells where the Trx1 spot was 0.223 units in the control and not detected in the thymol treatment. Trx 1 is an active oxidation-reduction protein that has been found to be involved in cell division in E. coli, which suggests thymol may play a role in the inhibition of bacterial population growth (Kumar et al., 2004). Trx1 refolds citrate synthase, an essential enzyme in the TCA cycle, and by downregulating Trx1 with thymol, citrate synthase was not present. In addition, enzymes of the reverse TCA cycle were upregulated in the thymol treatment such as an increase of citrate lyase from 0.08 units to 0.654 . Acetate kinase was also reduced from 0.567 units to 0.19 units within Salmonella. These results may not be replicated in Campylobacter due to its incomplete glycolytic pathways and studies investigating the use of EOs to alter the proteome of Campylobacter should be performed.

Another proposed mechanism for the effect of EOs on bacteria such as Campylobacter is their potential to disrupt the outer membrane and initiate cell lysis (O’Bryan et al., 2015). Attributed largely to EOs hydrophobicity, the outer membrane lipids may be disrupted, sheared, or penetrated, allowing for an increase in permeability (Fisher and Phillips, 2009; Brenes and Roura, 2010; Guinoiseau et al., 2010). Carvacrol and thymol, in $200 \mathrm{mg} / \mathrm{L}$ concentrations, have been demonstrated to inhibit E. coli through fluorescent flow cytometry ( $\mathrm{Xu}$ et al., 2008). The mechanism proposed in this study, supported by Helander et al. (1998), was that EOs disrupt the lipopolysaccharides membrane structure and alter the proton gradient (Xu et al., 2008). This effect may not occur in Campylobacter spp. due to their reliance on fermentation pathways and would have to be investigated (Line et al., 2010). Alterations of the lipopolysaccharide membrane can still lead to disruption of the cytoplasmic membrane and cell lysis (Xu et al., 2008). Electron microscopy has demonstrated the $E$. coli treated with oregano oil resulted in cell membrane collapse and leakage of contents (Sikkema et al., 1995; De Sousa et al., 2012). Cumin derived p-cymene has been demonstrated to swell bacterial cell membranes and has been suggested to be used synergistically with carvacrol to lyse bacterial membranes (Ultee et al., 2002). Other phenolic compounds have been observed to demonstrate this effect on the bacterial membrane (Cosentino et al., 1999; Juliano et al., 2000; Lambert et al., 2001; Brenes and Roura, 2010).

Essential oils have also been shown to impact Gram-positive organisms (Si et al., 2006). Cinnamaldehyde and eugenol, only when used in combination, were shown to inhibit Staphylococcus, Micrococcus, and Bacillus (Moleyar and Narasimham, 1992). Moreover, when considering the 300 commercially viable EOs, it is quite likely not all EOs may operate under the same mechanism (Diaz-Sanchez et al., 2015). They may even operate in concert with a series of mechanisms that represent contradictory activities against bacterial cellular processes. While some EOs blends promote the growth of beneficial bacteria others have inhibited beneficial bacteria such as Lactobacillus, and even some Bacillus species (Kivanç et al., 1991; Manzanilla et al., 2001; Delaquis et al., 2002; Jamroz et al., 2003; Donsi et al., 2011). Furthermore, the antimicrobial activity may not be attributable to one specific mechanism (Skandamis et al., 2001; Carson et al., 2002). When considering all of the proposed mechanisms it seems more than likely that multiple mechanisms are responsible for the effect of EOs against pathogens including Campylobacter (Diaz-Sanchez et al., 2015). As a consequence, the impact of EO blends on Campylobacter populations may vary considerably in pre and post-harvest applications. 


\section{ANTIMICROBIAL EFFECTS OF EOs ON Campylobacter IN POULTRY PRE-HARVEST ENVIRONMENTS}

\section{Transmission and Colonization of Campylobacter in the Poultry GIT}

The use of EOs in pre-harvest environments has focused on preventing pathogen colonization or reducing their concentration in the GIT (Brenes and Roura, 2010). Campylobacter resides in the intestinal mucosa of the avian GIT and can be rapidly transmitted throughout a flock via the drinking water and fecal-oral route (Montrose et al., 1985; Beery et al., 1988; Keener et al., 2004). Campylobacter virulence factors that impact colonization include, motA, fliA, $j l p A$, and $r a c R$ and were discussed in Upadhyay et al. (2017) and reviewed in Bolton (2015). While there is still controversy over how and when Campylobacter colonize the ceca, the most common route is believed to be horizontal transmission throughout the flock (Cox et al., 2010; Silva et al., 2011). Vertical transmission has been reported from parent to fertile egg and studies have detected 35\% inoculation of the progeny (Clark and Bueschkens, 1985; Chuma et al., 1994; Cox et al., 2010). However, in a study with 60,000 progeny-parent breeders there was no evidence of vertical transmission, and therefore more emphasis is placed on Campylobacter colonization occurring through horizontal or environmental transmission (Callicott et al., 2006; Silva et al., 2011). Campylobacter can spread through water supplies, insects, litter, rodents, fecal content, and from bird to bird contact (Aarts et al., 1995; Adkin et al., 2006; Horrocks et al., 2009). Campylobacter colonization is usually detected at approximately 3 weeks of age and with concentrations rapidly reaching $10^{7} \mathrm{CFU} / \mathrm{g}$ (Corry and Atabay, 2001). The ceca, containing up to $10^{9} \mathrm{CFU} / \mathrm{g}$, contains the largest concentration of Campylobacter within the avian GIT due to the abundance of nutrients, including amino acids, and the temperature in the avian ceca being approximately $42^{\circ} \mathrm{C}$, which is optimal for Campylobacter growth (Stern, 2008; Gerwe et al., 2010; Troxell et al., 2015). The ceca are closed pouches between the ileum and the colon (Duke, 1986). This site is an important consideration for food safety as the ceca may rupture during poultry processing leading to contamination of the finished poultry product if not properly handled (Hargis et al., 1995).

\section{EOs and Campylobacter in the Ceca}

When examining responses of cecal contents in vitro, $20 \mathrm{mM}$ (approximately $0.3 \%$ ) of cinnamaldehyde, thymol, eugenol, or carvacrol were all independently effective in significantly reducing Campylobacter concentrations after $15 \mathrm{~s}$ of incubation (Kollanoor-Johny et al., 2010). By $8 \mathrm{~h}$ incubation, $10 \mathrm{mM}$ concentrations of cinnamaldehyde, thymol, eugenol, or carvacrol were sufficient in decreasing C. jejuni by at least 5-log colony forming units (CFUs)/mL (Kollanoor-Johny et al., 2010). Kurekci et al. (2013) spiked $3 \times 10^{8} \mathrm{CFU} / \mathrm{ml}$ of C. jejuni C338 into 20-day old chicken cecal contents that previously contained no detectable Campylobacter. One gram of cecal contents was mixed with $19 \mathrm{~mL}$ of an anaerobic media containing 0.05 or $0.025 \%$ lemon myrtle oil. The media comprised of $\mathrm{MgSO}_{4} 7 \mathrm{H}_{2} \mathrm{O}$, $0.5 \mathrm{~g} ; \mathrm{CaCl}_{2}, 0.02 \mathrm{~g} ; \mathrm{K}_{2} \mathrm{HPO}_{4}, 0.75 \mathrm{~g} ; \mathrm{NaH}_{2} \mathrm{PO}_{4} \mathrm{H}_{2} \mathrm{O}, 0.25 \mathrm{~g}$; yeast extract $1.0 \mathrm{~g}$; resazurin, $1 \mathrm{mg}$; and cysteine- $\mathrm{HCl}, 0.5 \mathrm{~g}$ per liter of deionized water was kept in an anaerobic chamber (Laanbroek et al., 1977). Cultures were incubated for $48 \mathrm{~h}$ at $39^{\circ} \mathrm{C}$ and plated. While the positive control retained a concentration of $6.11 \log \mathrm{CFU} / \mathrm{mL}$, broths containing EOs reduced Campylobacter concentrations below the limit of detection (less than $3.3 \log \mathrm{CFU} / \mathrm{mL}$ ).

Caprylic acid, a component of coconut oil and palm kernel oil, significantly reduced Campylobacter cecal concentrations when administered in feed at concentrations below 1\% (Los Santos et al., 2008, 2009). This was observed in market age and 10-day old broilers and did not affect FCR or BWG. However, the in vivo Campylobacter reducing effects of caprylic acid have been demonstrated to be mitigated when applied as caprylate in feed and water (Hermans et al., 2010; Metcalf et al., 2011).

Arsi et al. (2014) investigated the use of thymol, carvacrol, or a combination, as a feed amendment to prevent C. jejuni colonization. Ten birds per treatment were inoculated on day 3 with a 5-strain mixture of $C$. jejuni that were previously isolated from chicken ceca and susceptible to ciprofloxacin or fluoroquinolone. Birds were euthanized on day 10. Cecal Campylobacter counts were enumerated using Campylobacter Line agar (Line, 2001) and confirmed using latex agglutination. Individual strains were not distinguished. Four trials were performed of this experiment with the only difference between trials was the inclusion of a $2 \%$ (Trials 1 and 2) or $0.125 \%$ treatment group and the use of EO combinations (Trials 3 and 4). While significant reductions of Campylobacter in the $0.25 \%$ thymol, $2 \%$ thymol, $1 \%$ carvacrol, and $0.5 \%$ thymol and carvacrol treatments existed, these reductions were not observed across all trials and were not detected in birds fed other concentrations. Thymol, at a concentration of $0.25 \%$, reduced Campylobacter by $0.6 \log \mathrm{CFU} / \mathrm{mL}$ cecal contents during only one trial out of four. A $2 \log$ CFU reduction was observed with $2 \%$ thymol for only one trial out of two. Additionally, $2 \log \mathrm{CFU} / \mathrm{mL}$ cecal contents were observed for one trial using $0.5 \%$ thymol and carvacrol, but this was not repeated.

Campylobacter jejuni-infected broilers in a seeder model that were given feed coated in $0.3 \%$ trans-cinnamaldehyde did not exhibit any significant reduction in Campylobacter cecal populations after 1 week (Hermans et al., 2011a). In this model, six pens were set up each containing nine chickens with half of the pens receiving cinnamaldehyde. At day 15 , three chicks per pen were given $10^{8} \mathrm{CFU} / \mathrm{mL}$ of C. jejuni KC 40. At day 21, the chickens were euthanized. All ceca within the treatment groups contained $C$. jejuni. When the cecal populations of Campylobacter were averaged per pen, significant differences between treatment and control group were not observed. Cinnamaldehyde degrades quickly in the upper GIT of piglets, and this may explain the lack of differences within the populations for the chicken-based studies as well (Michiels et al., 2008). A commercial blend of garlic and cinnamon, Alliin Plus (Orffa, Werkendam, 
Netherlands), was found to cause a $1 \log$ CFU/g reduction of Campylobacter cecal counts 3 days post-infection (day 11) but no significant effects were detected on day 35 or day 42 (Guyard-Nicodeme et al., 2015).

\section{Combinations of EOs and Other Antimicrobial Compounds}

Numerous alternative antimicrobials have been implemented in pre-harvest poultry environments to inhibit foodborne pathogens such as Campylobacter (Umaraw et al., 2017). These include bacteriophages, bacteriocins, prebiotics, probiotics, and organic acids (OAs), and EOs (van der Wielen et al., 2000; Edris, 2007; Umaraw et al., 2017). With different mechanisms of action, these remediation techniques may have synergistic potential. As such, this section will review combinations of EOs and other alternative non-EO antimicrobials, notably OAs against Campylobacter.

Gracia et al. (2015) evaluated the effectiveness of a $0.03 \%$ blend of thymol, eugenol, piperine, and benzoic acid or $0.08 \%$ garlic oil. Chickens were inoculated with $0.1 \mathrm{~mL}$ of $10^{5}$ $\mathrm{CFU} / \mathrm{mL}$ of C. jejuni at day 14 by Gracia et al. (2015). On days 21 to 42, birds in treatment groups were administered the EOs benzoic acid blend or garlic oil. In the control groups, C. jejuni populations were 7.33 and $7.38 \mathrm{log} \mathrm{CFU} / \mathrm{g}$. In the treatment group with the EOs blend, concentrations of C. jejuni were $7.66 \mathrm{log} \mathrm{CFU} / \mathrm{g}$, and in the garlic oil treatment, C. jejuni concentrations were $7.26 \log \mathrm{CFU} / \mathrm{g}$. Both these treatments were not able to statistically reduce Campylobacter concentrations.

An OA and EO treatment combination was administered to broilers by Thibodeau et al. (2014). This blend contained sorbate, fumarate, and thymol. Sorbate has been demonstrated to disrupt the cell wall of Gram-negative bacteria and lower $\mathrm{pH}$ of the GIT, while fumarate indirectly affects intestinal bacteria by lowering the $\mathrm{pH}$ of the stomach (Diener et al., 1993; Papatsiros et al., 2013; Dittoe et al., 2018). Because these OAs operate differently than the proposed EO mechanism, they may have synergistic potential, although fumarate has been demonstrated to be metabolized by C. jejuni (Hinton, 2006). Feed was amended with $500 \mathrm{ppm}$ of the EOs-OA blend and provided to broilers (Thibodeau et al., 2014). On day 14, these birds were administered $1 \mathrm{~mL}$ of inoculum containing $10^{5}$ $\mathrm{CFU} / \mathrm{mL}$ of two strains of Campylobacter (designated \#1 and 2). One, two, and three weeks after inoculation Campylobacter concentrations were enumerated in the ceca and on the whole carcass post-processing. This experiment was repeated using a different set of strains ( 3 and 4 ) with lower adhesion properties. In the trial with strains 1 and 2, counts of Campylobacter were not significantly different when compared to the control. In the trial with strains 3 and 4 , cecal populations were significantly higher 3 weeks after inoculation by approximately $1.5 \log \mathrm{CFU} / \mathrm{g}$, but carcass rinses were significantly lower by approximately $2 \log \mathrm{CFU} / \mathrm{mL}$. This suggests the adhesion properties may impact the efficacy of the EO treatment, however other variations between the strains may be impacting the results. These adhesion properties are necessary for binding to the intestinal cell wall within poultry, which may also be impacted by EOs (Vidanarachchi et al., 2005).

\section{Impacts on the Intestinal Mucosal Layer and Microbiota}

The proposed mechanism of protecting the intestinal mucosa from colonization has been demonstrated by studies involving prebiotics, which are typically oligosaccharides utilized for the protection of the mucosal layer or improvement of the colonization of beneficial bacteria (Lee et al., 2002; Vidanarachchi et al., 2005; Johnson et al., 2015; Roto et al., 2015; Micciche et al., 2018a; Ricke, 2018). The intestinal mucosa consists of the epithelium and lymphoid tissue along with the mucus that is primarily comprised of glycoproteins referred to as mucins (Montagne et al., 2003). Mucins range from 0.5 to $20 \mathrm{Mda}$ in size, and the saccharide component of the avian mucins includes fucose (15.29 $\mathrm{ng} / \mu \mathrm{g}$ of mucin), $\mathrm{N}$-acetyl-galactosamine (5.3 ng/ $\mu \mathrm{g}), \quad N$-acetyl-glucosamine (47.72 $\mathrm{ng} / \mu \mathrm{g})$, galactose

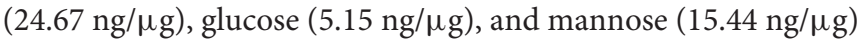
(Bansil and Turner, 2006; Looft et al., 2019). These carbohydrates comprise $80 \%$ of the glycoprotein weight and are oligosaccharide chains consisting of 5 to 15 monomers attached to the protein core (Bansil and Turner, 2006). Approximately 60\% of the protein core consists of serine, threonine, and proline repeats and this is interspersed with approximately $10 \%$ cysteine and connect to the oligosaccharide chains via O-glycosidic bonds (Perez-Vilar and Hill, 1999; Gongqiao et al., 2003; Bansil and Turner, 2006).

Mucus protects the GIT epithelial layer from exposure to the digestive enzymes and corrosive gastric fluids and serves as a matrix for the entrapment of bacteria (Turnberg, 1987; Perez-Vilar and Hill, 1999; Lien et al., 2001). For instance, L-fucose, serine, and cysteine of mucins have been demonstrated to exhibit a positive chemotaxis response on C. jejuni, attracting the bacteria to the chemical compound (Hugdahl et al., 1988). Campylobacter jejuni have also been found to preferentially attach to avian mucins compared to cow, deer, horses, mice, sheep, pigs, and rat mucins (Naughton et al., 2013). These entrapped bacteria can, in turn, modulate gene expression of epithelial cells, impact lymphoid cells, and affect the overall health of the host by degrading complex oligosaccharides and producing short-chain fatty acids (SCFAs) (Hooper et al., 2001; Guarner and Malagelada, 2003; Sergeant et al., 2014). In chickens, the intestinal microbiota within this mucosal layer is diverse and complex, and in the ceca, the microbiome is primarily colonized by Firmicutes, Bacteriodetes, and Proteobacteria (Wei et al., 2013).

Detectable Campylobacter colonization usually occurs after 14 days of age and growth is often correlated with the presence of other microbiota, although Campylobacter's interaction with the microbiome is poorly characterized (Hermans et al., 2011b; Indikova et al., 2015; Thibodeau et al., 2015). In humans, C. jejuni colonization is associated with a decrease of the butyrate producer, Faecalibacterium, which suggests these two bacteria may share a similar ecological niche (Hansen et al., 2014; Thibodeau et al., 2015). Lower abundances of Lactobacillus and Corynebacterium have also been associated with C. jejuni colonization, along with higher concentrations of Streptococcus 
and Ruminococcaceae (Kaakoush et al., 2014). These findings indicate that there is an interaction between the intestinal microbiota and C. jejuni colonization. Therefore, utilizing EOs to alter the mucosal layer, possibly through microbiome modulation, or interfering with $C$. jejuni binding properties, would be beneficial to preventing intestinal colonization and downstream product contamination.

One mechanism for bacterial adhesion to the poultry GIT is through lectin-carbohydrate receptors (Vidanarachchi et al., 2005). Mutants of C. jejuni without CadF protein synthesis capabilities are unable to produce a lectin protein that specifically binds to fibronectin (Ziprin et al., 1999; Rubinchik et al., 2012). CadF is a membrane-bound protein that mediates the binding of Campylobacter to fibronectin within the intestinal mucosa, which is necessary for Campylobacter colonization (Quaroni et al., 1978; Ziprin et al., 1999; Monteville et al., 2003). CadF operates by modulating the level of tyrosine phosphorylation of paxillin, which is a focal adhesion signaling molecule (Konkel et al., 2005). These mutants were unable to colonize the poultry GIT, because of the absence of the carbohydrate binding adhesion protein (Ziprin et al., 1999). Piva and Rossi (1998) postulated that oligosaccharides, such as mannan-oligosaccharides, would bind to enterocyte receptors on pathogenic cell walls which would also prevent colonization (Micciche et al., 2018a). Essential oils have not yet been found to inhibit colonization of Campylobacter through preventing lectin-carbohydrate binding.

Similar to prebiotics, such as pectin and oligosaccharides, EOs have been shown to improve the qualities of the mucosal layer of the intestine (Bengmark, 1998; Vidanarachchi et al., 2005; Wang et al., 2016). As with EOs impacting the immune response in layer hens against $\mathrm{NCV}$, prebiotics has been shown to upregulate immune response cells in the intestinal mucosal such as CD4+ and CD8+ (Lourenço et al., 2015). Immune responses by prebiotic supplementation have been extensively reviewed in Hardy et al. (2013). Additionally, mucins, which can subvert the adherence of pathogenic E. coli have been upregulated by Lactobacillus plantarum $299 \mathrm{~V}$ and Lactobacillus rhamnosus GG (Mack et al., 1999; Hardy et al., 2013). Lactobacillus can be promoted by prebiotics and potentially EOs, and this can potentially create a positive feedback loop as mucins have also been demonstrated to improve bacterial growth as they can be up to $90 \%$ carbohydrate by weight (Perez-Vilar and Hill, 1999; Manzanilla et al., 2004; Eeckhaut et al., 2008; Emami et al., 2012; Hardy et al., 2013; Yousaf et al., 2017).

The influence by EOs on the intestine has primarily focused on crypt depth and mucosal thickness (Vidanarachchi et al., 2005). Broiler diets supplemented with $100 \mathrm{mg} / \mathrm{kg}$ of $5 \%$ carvacrol, $3 \%$ cinnamaldehyde, and $2 \%$ of capsicum oleoresin exhibited an impact on the jejunal mucosa. A higher jejunal wall villi layer was observed along with an increase in thickness of the mucosa layer, which helps prevent bacterial colonization (Jamroz et al., 2006). This is because while the thicker mucosa may potentially entrap more bacteria, a thick mucosal layer may also prevent adhesion to the intestinal villi and subsequent GIT colonization by decreasing the proximity of bacteria to the intestinal binding sites (Turner, 2009). Broilers supplemented with thymol or garlic powder $(1 \mathrm{~g} / \mathrm{kg})$ in their diet showed similar effects in the intestinal morphology (Demir et al., 2005). However, in pigs, villi length was either decreased or unaffected by supplementation of EOs (Namkung et al., 2004; Nofrarias et al., 2006; Kroismayr et al., 2008). Prevention of bacterial adhesion would be beneficial for inhibiting Campylobacter but could have deleterious effects on nutrient absorption due to changes within the GIT microbial community. For instance, SCFA producing bacteria, such as Lactobacillus and Bifidobacterium, have been shown to have positive impacts on nutrient absorption and overall bird health and antimicrobial strategies that prevent their growth could be detrimental. However, EOs have been reported to improve the colonization of bacteria that are non-pathogenic and may benefit the overall health of the microbiota (Wenk, 2003; Windisch and Kroismayr, 2007).

Growth rate improvement of Lactobacillus, Bifidobacteria, and other probiotic bacteria in avian hosts is viewed as a potential mechanism inhibiting avian colonization of foodborne diseases such as Campylobacter (Santini et al., 2010). In simulated environments, Lactobacillus has been shown to inhibit the colonization of undesired bacteria such as Campylobacter (Chang and Chen, 2000). Four strains of Lactobacillus $\left(10^{4} / \mathrm{ml}\right)$ and C. jejuni $\left(10^{6} / \mathrm{mL}\right)$ were added to a simulated chicken digestive system consisting of $\mathrm{pH}$ adjusted veronal buffers. Veronal buffer contains $0.15 \mathrm{mM} \mathrm{CaCl}_{2}, 141 \mathrm{mM} \mathrm{NaCl}, 0.5 \mathrm{mM} \mathrm{MgCl}_{2}$, $0.1 \%$ gelatin, $1.8 \mathrm{mM}$ sodium barbital, and $3.1 \mathrm{mM}$ barbituric acid (Sigma-Aldrich; St. Louis, MO, United States) and was subsequently adjusted to a $\mathrm{pH}$ of $4.5,4.4,2.6,6.2$, and 6.3 to represent the crop, proventriculus, gizzard, small intestine, and large intestine, respectively. A simulated chicken digestive system was also created by adjusting each veronal buffer with $0.1 \mathrm{~N} \mathrm{HCl}$ or with veronal buffer at $\mathrm{pH} 9.6$ to simulate passage within each intestinal organ. Within individually simulated GIT compartments, and the simulated chicken digestive system as a whole, significant Campylobacter reductions were observed compared to the control with no addition of Lactobacillus. In the gizzard, while a reduction from approximately $6 \log$ $\mathrm{CFU} / \mathrm{mL}$ to approximately $4 \log \mathrm{CFU} / \mathrm{mL}$ of Campylobacter was observed within $90 \mathrm{~min}$, likely due to the low $\mathrm{pH}$, a $4 \log$ reduction was observed when $6 \log \mathrm{CFU} / \mathrm{mL}$ of Lactobacillus was added. These results might in part be due to the ability for Lactobacillus to produce bacteriocins that are inhibitory to C. jejuni (Messaoudi et al., 2012). Stern et al. (2006) applied purified bacteriocin OR-7, produced by Lactobacillus salivarius NRRL B-30514, to the feed of broilers that were challenged with C. jejuni. Compared to controls, $6 \mathrm{log} \mathrm{CFU} / \mathrm{g}$ cecal content reductions were observed independently of the C. jejuni strain utilized.

Lactobacillus has also been known to produce SCFAs that can reduce C. jejuni populations (Awad et al., 2018). When SCFAs were tested in vitro, butyrate was determined to be bactericidal toward C. jejuni at a concentration of $12.5 \mathrm{mM}$, and acetate and propionate were bacteriostatic at $50 \mathrm{mM}$ (Van Deun et al., 2008). Campylobacter has been demonstrated to produce acetate as a by-product of serine catabolism and utilize it as an energy source, which could explain the variation between it and butyrate inhibition (Parker et al., 2007; Stahl et al., 2012). This does not explain the variation between 
propionate and butyrate. While it has been demonstrated that C. jejuni can metabolize acetate and the OA lactate, no known pathways have been elucidated for the transport or metabolism of propionate or butyrate (Wright et al., 2009; Thomas et al., 2011; Anand et al., 2016).

Lactobacillus and Enterococcus strains, which can produce SCFAs, were tested in vitro and were also found to be inhibitory to C. jejuni (Chaveerach et al., 2004; Allameh et al., 2017). Chaveerach et al. (2004) cultured five Enterococcus and five Lactobacillus strains from healthy chickens and grew them in Mueller-Hinton broth. The broth was subsequently centrifuged, and the supernatant was separated from the bacteria. The supernatant was neutralized to a $\mathrm{pH}$ of 6.2 and treated with pronase and catalase to break down bacteriocins and hydrogen peroxide, respectively. Once the supernatants were confirmed to be free of bacteria, they were applied in a well-diffusion agar assay against 10 individual strains of $C$. jejuni. The supernatant with the highest bactericidal activity came from a Lactobacillus strain labeled P93, which produced a zone of inhibition of 9 to $15 \mathrm{~mm}$ and was able to impact the growth of all 10 strains of C. jejuni. This strain was also grown in co-culture with $C$. jejuni $\mathrm{C} 2150$, each at an initial inoculum of $7 \log \mathrm{CFU} / \mathrm{mL}$, and after $48 \mathrm{~h}$, Campylobacter was not isolated from the culture. Campylobacter jejuni C2150 was also grown with Lactobacillus strain P104, which did not exhibit any antimicrobial effects in the well-diffusion agar, but by $72 \mathrm{~h}$ Campylobacter concentrations were approximately $1.5 \mathrm{log}$ $\mathrm{CFU} / \mathrm{mL}$ lower than the positive control at $7.5 \mathrm{CFU} / \mathrm{mL}$. This study indicates that not only can Lactobacillus directly compete for nutrients and colonization niche with Campylobacter, but some strains can also employ antimicrobials to reduce their population numbers further.

Plant-derived compounds such as cumin, oregano, and extracts of capsaicin, cinnamaldehyde, and carvacrol have been shown to improve the growth of Lactobacillus, Bifidobacteria, and Enterococcus, and therefore may indirectly impact pathogen concentrations through competitive exclusion (Kivanç et al., 1991; Jamroz et al., 2003; Manzanilla et al., 2004). Manzanilla et al. (2001) demonstrated how XT, a mixture of carvacrol, cinnamaldehyde, and capsaicin, increased Lactobacillus cecal counts in post-weaning pigs when provided in the feed. However, these interactions are complicated as the addition of C. jejuni has been attributed to an increase in Bifidobacterium (Thibodeau et al., 2015). Further research must be performed to determine if, or which, EOs exhibit antimicrobial qualities against Campylobacter that may also simultaneously support GIT bacteria that are antagonistic to Campylobacter. While EOs do not appear to operate as substrates for Lactobacillus or other probiotics and are therefore not prebiotics, their indirect impacts on the intestinal mucosal layer promote an environment suitable for the growth of "beneficial" bacteria, which in turn, have the potential to reduce Campylobacter concentrations. Other studies found that EOs, including cumin, orange oil, and oregano, have an inhibitory effect on Lactobacillus spp. (Kivanç et al., 1991; Elgayyar et al., 2001; Delaquis et al., 2002; Chalova et al., 2010). As such, there are limitations for the application of EOs to poultry that must be addressed.

\section{Potential Limitations and Future Directions for Preharvest EOs Application}

There appears to be inconsistency in responses of birds infected by Campylobacter when administered EOs compared to in vitro responses as well as among individual bird trials. Understanding the underlying factors and potential limitations may give insight into how EOs can be applied in the future. One primary limitation of EOs is that they can be rapidly absorbed in the GIT (Meunier et al., 2006). This rapid absorption has been observed in pigs and humans (Kohlert et al., 2002; Meunier et al., 2006). Absorption by the stomach and small intestine before they can affect cecal concentrations may be occuring in in vivo studies (Arsi et al., 2014). To test this potential limitation, intestinal absorption resistant EOs derivatives can be applied. Thymol- $\beta$-d-glucopyranoside is more resistant to intestinal absorption than thymol and has been shown to have similar antimicrobial effects in vitro (Epps et al., 2015). However, while a $1 \log$ reduction of Campylobacter was observed in the crops of market-aged broilers with this absorption-resistant compound, no significant impacts were found in the ceca with either thymol-based treatment (Epps et al., 2015).

Microencapsulation may also be utilized (Calo et al., 2015). Microencapsulation is a process in which liquid particles are surrounded in polymeric compounds (Bansode et al., 2010). Typical water-soluble coating materials can include gelatin, gum arabic, and polyacrylic acid (Jyothi et al., 2012). The intention of microencapsulation with preharvest remediation techniques is to prevent the therapeutic compound from absorption before reaching the target area within the GIT (Van Immerseel et al., 2004). For instance, Pan et al. (2014) found that encapsulated thymol inhibited pathogens more effectively in milk due to enhanced solubility. As such, microencapsulated EOs have been suggested as a methodology for improving the in vivo effects of EOs (Calo et al., 2015). Utilizing a feed-based microencapsulated blend of thymol and eugenol, along with propionic and sorbic acids, Grilli et al. (2013) was able to reduce C. jejuni in layer hens. During a 42-day trial, birds were provided this blend, labeled CTR, at varying concentrations $(0.1,0.3,0.5$, or $1.0 \%)$, and were infected with $10^{7} \mathrm{CFU} / \mathrm{mL}$ C. jejuni on day 22. Campylobacter concentrations were measured by plating cecal contents onto modified Charcoal-Cefoperazone-Deoxycholate Agar (mCCDA). The CTR blend was effective in reducing $C$. jejuni at all concentrations $(0.1,0.3,0.5$, or $1.0 \%)$ on days 35 and 43 , with $1 \%$ CTR exhibiting a $5 \log \mathrm{CFU} / \mathrm{g}$ reduction at day 42 compared to the control. At day 42 the $0.1 \%$ concentration reduced Campylobacter populations by $3 \mathrm{log} \mathrm{CFU} / \mathrm{g}$. In a second experiment utilizing either 0.1 or $0.3 \%$ of this blend, birds were given either the blend before or after the day 22 infection with Campylobacter. Statistically significant reductions were still observed within each treatment group, except with $0.1 \%$ CTR at day 35 , but the reductions were significantly lower for the group given the treatment after infection instead of before. The CTR blend at a concentration of $0.3 \%$ given from day 0 to 21 reduced C. jejuni by $1.5 \log \mathrm{CFU} / \mathrm{g}$ at day 35 where $3 \log \mathrm{CFU} / \mathrm{g}$ reductions were observed when the $0.3 \%$ CTR blend was applied 
on day 22. However, in a cecal loop model study by Hermans et al. (2011a), involving direct injection of the trans-cinnamaldehyde into ceca infected with $C$. jejuni they failed to detect significant reductions in Campylobacter concentrations. This indicates that the absorption of the EOs in the upper GIT is not the only reason for variation between in vivo and in vitro trials (Arsi et al., 2014). Further experiments utilizing microencapsulation of combined EO blends, along with comparisons with their unencapsulated counterparts, is necessary to determine the specific effectiveness of utilizing microencapsulation.

Additionally, the observed reductions using blends of EOs can help reduce the incidence of Campylobacter at time of slaughter, which can lead to reductions of human incidences of campylobacteriosis (Rosenquist et al., 2003; Chapman et al., 2016). Furthermore, an investigation into EOs impact on the GIT microbiome may also represent a pertinent future direction. For instance, increasing the concentrations of certain members of the GIT microbiome through EOs may generate a GIT less suitable or more hostile for initial C. jejuni colonization (Kaakoush et al., 2014). Once the interactions between C. jejuni, the microbiome, and EOs remediation are fully elucidated a more targeted remediation technique may be possible. For instance, specific EOs blends could be designed to modulate the microbiome to prevent $C$. jejuni colonization. While in vivo EOs application may not be able to eliminate Campylobacter concentrations at the time of slaughter, it does provide a hurdle that the bacteria must overcome before contamination of the final product (Leistner, 2000; Holley and Patel, 2005).

\section{ANTIMICROBIAL EFFECTS OF EOS ON Campylobacter IN POULTRY PROCESSING}

Campylobacter contamination on poultry products is one of the more common causes of campylobacteriosis in humans (Keener et al., 2004). Incidence rates in a study of 425 broiler carcasses over 12 months revealed $87.5 \%$ of the post-chill carcasses were contaminated with Campylobacter in a French slaughterhouse (Hue et al., 2010). In the United States, 52\% of post-chill carcasses $(n=325)$ were contaminated with Campylobacter with $100 \%$ of the carcasses being contaminated pre-chill (Son et al., 2007). The most frequent method for this contamination event is for the GIT to rupture during processing and contaminants to spill onto the carcass (Berrang et al., 2001). If not properly treated during carcass rinses, cross-contamination can occur, especially within chiller tanks (Bashor et al., 2004). As such, to prevent cross-contamination, it is vital that carcass rinses and sprays be applied as appropriate sanitation techniques. Essential oils may serve as an alternative sanitizer for processing washes.

In vitro laboratory experiments may have more relevance to post-harvest interventions than pre-harvest mediations due to the complexity of the poultry GIT that cannot easily be modeled in a laboratory environment (White et al., 1997). For instance, in a series of benchtop studies orange oil was found to be inhibitory to C. jejuni, C. coli, L. monocytogenes, Salmonella, and Pseudomonas (O'Bryan et al., 2008; Nannapaneni et al., 2009; Chalova et al., 2010). Nannapaneni et al. (2009) tested seven orange oil fractions on 3 Arcobacter strains and 21 Campylobacter strains, including 14 C. jejuni strains, four of which were isolated from poultry. When viewed on disk diffusion agar, cold pressed (CP) terpeneless Valencia orange oil produced the largest zones of inhibition (in $\mathrm{mm}$ ) of C. jejuni including those isolated in poultry, whereas other orange oil fractions produced more limited zones of inhibition. Valencia orange oil was also reported to be inhibitory toward C. coli and Arcobacter. Kurekci et al. (2013) found tea tree oil at a concentration of $0.001 \%$ to be inhibitory against two strains of C. jejuni on nutrient agar. Wild carrot oil, when used in agar plates as an antimicrobial against Campylobacter spp. including a multidrug-resistant strain, C. jejuni 99T403, exhibited a minimum inhibitory concentration (MIC) of 125 to $500 \mu \mathrm{g} / \mathrm{mL}$ depending on the species or strain (Rossi et al., 2007). Isoeugenol and E-methyl isoeugenol are extracts of carrot oil and when tested against C. jejuni resulted in an MIC of $125 \mu \mathrm{g} / \mathrm{mL}$ (Rossi et al., 2007). Thymol, in a concentration of $0.25 \mu \mathrm{mol} / \mathrm{mL}$, reduced C. jejuni and C. coli by 5 logs $\mathrm{CFU} / \mathrm{mL}$ in Bolton broth from an initial concentration of $7 \log \mathrm{CFU} / \mathrm{mL}$ (Anderson et al., 2009; Carocho et al., 2014). An EO extract from Origanum minutiflorum, composed primarily of carvacrol and p-cymene, has been shown to be effective in inhibiting $C$. jejuni in concentrations as low as $12.5 \mu \mathrm{g} / \mathrm{mL}$ on Mueller-Hinton agar (Aslim and Yucel, 2008). However, these MICs were strainspecific, as of the 12 C. jejuni strains tested, only C. jejuni 118d was inhibited at the concentration of $12.5 \mu \mathrm{g} / \mathrm{mL}$, while C. jejuni $113 \mathrm{k}, 7 \mathrm{~d}$, and $9 \mathrm{a}$ required $700 \mu \mathrm{g} / \mathrm{mL}$ to be inhibited (Aslim and Yucel, 2008). Cinnamon, clove, thyme, and bay leaf oils were found to be bacteriostatic at a concentration of $0.075 \%$ against C. jejuni, S. Enteritidis, E. coli, Staphylococcus aureus, and L. monocytogenes when tested in tryptic soy broth (TSB) (Smith-Palmer et al., 1998).

Other studies reported similar inhibitory and bacteriostatic effects of oregano, eucalyptus, marigold, ginger, jasmine, cedarwood, carrot, mugwort, bergamot, and other EOs, against Campylobacter and other foodborne pathogens (Friedman et al., 2002; Moreira et al., 2005; Fisher and Phillips, 2006; Thanissery et al., 2014). The MIC of EOs on other foodborne pathogens were collected and reviewed in Hyldgaard et al. (2012). Friedman et al. (2002) tested 119 EOs against C. jejuni, E. coli O157:H7, L. monocytogenes, and S. enterica in PBS for $60 \mathrm{~min}$ at $37^{\circ} \mathrm{C}\left(42^{\circ} \mathrm{C}\right.$ for $\mathrm{C}$. jejuni) followed by plating on appropriate media for each species, including an ironsupplemented Brucella agar for C. jejuni. The EO concentration that resulted in the bactericidal activity of a $50 \%$ CFU decrease relative to the control was determined for each EO bacterial species combination. Marigold taegetes $(0.003 \%)$, ginger root $(0.005 \%)$, jasmine $(0.006 \%)$, patchouli $(0.007 \%)$, and gardenia $(0.007 \%)$ were the most effective oils against C. jejuni RM1221 followed by cedarwood $(0.0075 \%)$, carrot seed $(0.0078 \%)$, celery seed $(0.0085 \%)$, mugwort $(0.009 \%)$, spikenard $(0.009 \%)$, and orange bitter oils $(0.009 \%)$. In this study, 39 EOs were tested against all four foodborne pathogens. When their bactericidal activities were averaged, the five most effective EOs were cinnamaldehyde $(0.03 \%)$, thymol $(0.05 \%)$, Spanish oregano 
(0.05\%), carvacrol (0.06\%), and Oregano origanum $(0.06 \%)$. Of these five EOs, C. jejuni was impacted the most by the lowest percent concentration compared to the other tested foodborne pathogens.

This suggests that not only may C. jejuni be a prime target for EO remediation, but EO that have not been extensively tested may be more optimal candidates to utilize, such as marigold and jasmine. Disk diffusion methods indicated that lemon, sweet orange and bergamot were effective against L. monocytogenes, S. aureus, B. cereus, E. coli O157:H7, and C. jejuni (Fisher and Phillips, 2006). Each oil was added to a $2 \mathrm{~cm}$ disk and then placed on agar plates in the presence of the bacteria of interest, with C. jejuni SR 117 being plated on Campylobacter agar base with $5 \%$ horse blood and incubated at $42^{\circ} \mathrm{C}$. No zones of inhibition were detected for C. jejuni when orange or citral was added. Bergamot produced a zone of inhibition of $23 \mathrm{~mm}$, and lemon produced a zone of inhibition of $18 \mathrm{~mm}$, which were the smallest zones compared to the other tested bacteria. The zone of inhibition for linalool was greater than $90 \mathrm{~mm}$. The MIC was also determined for bergamot (greater than 4\%), lemon (greater than $4 \%$ ), and linalool $(0.06 \%)$. While no zone of inhibition was visually detected for orange oil by Fisher and Phillips (2006), when orange oil was supplemented with thyme, the combination EOs demonstrated antimicrobial activity against Campylobacter (Thanissery et al., 2014). Similar to Fisher and Phillips (2006), a disk diffusion test was performed using thyme, orange, rosemary, clove, and a 1:1 ratio of thyme and orange oil. This was tested on C. jejuni 11601 MD, C. jejuni RM1221, and C. coli RM2228 along with a cocktail of the three strains. No visible growth on disk diffusion assay across all strains and in the cocktail was visualized when exposed to thyme or clove. For the cocktail, orange oil, rosemary, and the combination of thyme and orange oil produced zones of inhibition of 17 , 11 , and $20 \mathrm{~mm}$, respectively. A macro-broth dilution assay was also performed using Mueller Hinton broth to determine the MIC and minimum bactericidal concentration (MBC) of these oils. However, the exact MIC and MBC was not determined as $0.0008 \%$ concentrations of the oils were sufficient for inhibiting bacterial growth.

Synergistic effects have also been detected (Nguefack et al., 2012). For instance, a combination of oregano and thyme or oregano and cinnamaldehyde required $80 \%$ less EOs to produce the same inhibitory effects in nutrient broth with a Campylobacter growth supplement (Navarro et al., 2015). Thymol and geraniol reduced Clostridium difficile in feces at $500 \mathrm{ppm}$, which was five times the concentration utilized for a significant reduction in pure cultures. When $0.16 \mathrm{mg} / \mathrm{mL}$ of rosemary oil, consisting of carnosic acid, carnosol, and rosmarinic acid was applied in the laboratory, a $2 \log$ $\mathrm{CFU} / \mathrm{mL}$ reduction in C. jejuni was observed in Mueller-Hinton broth when the initial concentration was at $7 \log \mathrm{CFU} / \mathrm{mL}$ (Klancnik et al., 2009; Piskernik et al., 2011). However, four times the concentration was needed to achieve the same reduction in chicken meat juice, isolated from thawed previously frozen carcasses, unless supplemented with nisin, a bacteriocin (Piskernik et al., 2011). While the complete composition was not provided in Piskernik et al. (2011), it was suggested that lipids and proteins within the juice matrix might have partly inhibited the EO therapy. Burt (2004) suggested that the decreased EO effectiveness in the food matrix compared to the broth experiment may be because in an oil-in-water emulsion that allows the bacteria to grow as films and in colonies, which can shield interior cells from therapeutics. As a consequence, while in vitro laboratory models are important, to elucidate the potential impact of EOs, poultry product matrices as well as processing environments must be considered.

The use of EOs in the post-harvest environment has focused on their bactericidal activity within carcasses washes and finished products (Calo et al., 2015; Dima and Dima, 2015). A 0.5\% 50:50 mixture of thyme oil and orange oil was used in a marinade for chicken wings dip-inoculated with $10^{7} \mathrm{CFU} / \mathrm{mL}$ of a nalidixic acid resistant strain of $C$. coli (Thanissery and Smith, 2014). While cross-contamination events were observed via the marinade, C. coli concentrations on treated wings were reduced by $3.0 \log \mathrm{CFU} / \mathrm{mL}$, as determined through plating of rinsates. Skinless chicken breasts experimentally infected with $5 \times 10^{5}$ $\mathrm{CFU} / \mathrm{g}$ of $C$. jejuni were subjected to stinkwort $(0.2 \%$; Inula graveolens), bay leaf (0.6\%; Laurus nobilis), mastic tree $(0.6 \%$; Pistacia lentiscus), and winter savory (0.6\%; Atureja gontana) (Djenane et al., 2012). After 8 days of refrigerated storage under microaerophilic conditions, greater than $5 \mathrm{log} C F U / g$ reductions of $C$. jejuni were observed compared to the control inoculated with $5 \times 10^{5} \mathrm{CFU} / \mathrm{g}$. Sensory analysis indicated these EOs improved or did not impact the odor of the refrigerated samples according to a six member trained panel. Within $60 \mathrm{~s}, 0.06 \%$ linalool oil reduced $C$. jejuni on $2 \mathrm{~cm} \times 2 \mathrm{~cm}$ pieces of cabbage leaf and chicken skin by greater than $5 \log$ CFU and $2 \log$ CFU, respectively (Fisher and Phillips, 2006). Cold pressed Valencia orange oil has also been shown to reduce C. jejuni UAF 244 on retail chicken thighs and legs (Nannapaneni et al., 2009). Chicken thighs and legs were dipped in a $0.8 \%$ saline solution containing $10^{6} \mathrm{CFU} / \mathrm{mL}$ C. jejuni UAF 244 for $5 \mathrm{~min}$ and then submerged for $2 \mathrm{~min}$ in $20 \%$ (v/v) Valencia orange oil or $20 \%$ (v/v) limonene. The samples were then rinsed and plated. Across both types of chicken pieces, 1.5 to $2 \log \mathrm{CFU} / \mathrm{mL}$ reductions were observed, compared to the control. Treatments with limonene resulted in reductions without detectable recovery of viable bacterial cells, although the limit of detection was not provided by the authors. Moreover, while taste panels have found concentrations of orange oil up to $0.1 \%$ to be acceptable in milk, chicken patties and marinades, a $20 \%$ part dip has not been investigated for impacts on sensory characteristics (Jo et al., 2004; Fisher and Phillips, 2008; Rimini et al., 2014).

Other factors may confound EO efficacy toward Campylobacter in poultry products. For example, one major concern for poultry industries is the ability for pathogens to form biofilms (Srey et al., 2013). Biofilms are bacterial communities within a polysaccharide matrix that can readily form and attach on processing surfaces (Costerton, 1995; Donlan and Costerton, 2002). Biofilms can be difficult to remove by antimicrobials and processing sanitizers such as chlorine and peracetic acid, which are commonly used in the industry (Frank et al., 2003; Ryu and Beuchat, 2005; Scher et al., 2005; Deborde and Von Gunten, 2008). Campylobacter is known to form biofilms on 
stainless steel, polystyrene, and glass (Gunther and Chen, 2009). Coriander oil and its antimicrobial component linalool were found to affect biofilm formation of Campylobacter planktonic cells and pre-established biofilms (Duarte et al., 2016). When coriander and linalool were used at $2 \mu \mathrm{g} / \mathrm{mL}$ (approximately four times the MIC) C. jejuni and C. coli biofilms were reduced in size by 70 to $80 \%$ after 48 -h incubation in a crystal violet assay (Duarte et al., 2015, 2016). Even when using half the MIC, coriander, and linalool reduced the biofilm by 20 to $25 \%$ (Duarte et al., 2016). Results of biofilm inhibition varied more wildly from planktonic cells, but all concentrations (0.025 to $2 \mu \mathrm{g} / \mathrm{mL}$ ) successfully inhibited biofilm growth compared to the control, with linalool reducing some biofilm formation between 10 and 20\% of the control (Duarte et al., 2016). Thyme, oregano, and cinnamon EOs, when used at concentrations below the MIC, were also found effective against biofilms of Acinetobacter, Sphingomonas, and Stenotrophomonas spp. that were isolated from biofilms within the food industry (Szczepanski and Lipski, 2014). Sphingomonas biofilms were reduced by $50 \%$ by thyme oil at a concentration of $0.001 \%$ where the MIC was $0.008 \%$ (Szczepanski and Lipski, 2014). Similar results were found using thyme and balsam on Pseudomonas and S. aureus biofilms (Kavanaugh and Ribbeck, 2012; Kerekes et al., 2015).

\section{CONCLUSIONS}

The effectiveness of EOs in poultry has not been clearly defined yet. Product advantages have been noted in several studies, but studies also exist that display no impact on FCR or BWG. Other advantages of EOs include the potentially improved flavor of the carcass, antioxidant capacity, and improved feed digestibility. There is also evidence that EOs can be utilized in vitro to impact pathogen concentrations, including Campylobacter. However, this depends largely on the EO utilized as the mechanism(s) of action are not well-defined. With over 300 commercially available EOs, precisely elucidating the underlying mechanisms may prove difficult (Bajpai et al., 2012). Less information is available regarding the mechanistic role of EOs used in vivo. Their potential ability to improve amino acid absorption in the ileum may allow for generating a GIT environment unfavorable to Campylobacter in the ceca due to diminished substrate

\section{REFERENCES}

Aarts, H. J., Van Lith, L. A., and Jacobs-Reitsma, W. F. (1995). Discrepancy between Penner serotyping and polymerase chain reaction fingerprinting of Campylobacter isolated from poultry and other animal sources. Lett. Appl. Microbiol. 20, 371-374. doi: 10.1111/j.1472-765x.1995.tb01 324.x

Adkin, A., Hartnett, E., Jordan, L., Newell, D., and Davidson, H. (2006). Use of systematic review to assist the development of Campylobacter control strategies in broilers. J. Appl. Microbiol. 100, 306-315. doi: 10.1111/j.1365-2672.2005. 02781.x

Alcicek, A., Bozkurt, M., and Çabuk, M. (2004). The effect of a mixture of herbal essential oils, an organic acid or a probiotic on broiler performance. S. Afr. J. Anim. Sci. 34, 217-222.

Allameh, S. K., Ringø, E., Yusoff, F. M., Daud, H. M., and Ideris, A. (2017). Dietary supplement of Enterococcus faecalis on digestive enzyme activities, short availability, which is further downstream. To fully elucidate the impact EOs have on Campylobacter concentrations in vivo, further research on the mechanism(s) and effects of EOs must be performed.

More targeted delivery of EOs to certain sites in the avian GIT may be warranted as well. Microencapsulation may help to stabilize the chemical activity of the $\mathrm{EO}$ until it reaches its target site in the GIT, thus ensuring less variability. Microencapsulation also holds promise in addressing the intestinal absorption of an antimicrobial. However, investigations into the duration the encapsulated EOs remains in the GIT need to be performed to see when the remediation should be administered. In post-harvest settings, further studies should be performed involving the addition of EOs to sprays, washes, or within the chiller tank.

To determine the specific antimicrobial effects of EOs, the mechanism(s) must be elucidated. This is essential because, with a wide variety of EOs, there may be multiple mechanisms at work and thus synergistic potential which cannot be determined without proper identification of the mode of inhibitory action for each individual EO. Toward this effort, molecular approaches such as transcriptomics and proteomics may be employed to determine which pathways EOs inhibit will lead to further understanding of their impact on Campylobacter. While there have been suggestions to utilize EOs as a hurdle technology in poultry production pre- and post-harvest, mechanisms of action against Campylobacter and the optimal GIT locations and processing steps must first be established before any practical recommendations can be given.

\section{AUTHOR CONTRIBUTIONS}

All authors listed have made a substantial, direct and intellectual contribution to the work, and approved it for publication.

\section{FUNDING}

AM was supported by a Distinguished Doctoral Fellowship and support from the Department of Food Science at the University of Arkansas.

chain fatty acid production, immune system response and disease resistance of Javanese carp (Puntius gonionotus, Bleeker 1850). Aquac. Nutr. 23, 331-338. doi: 10.1111/anu.12397

Allen, K. J., and Griffiths, M. W. (2001). Effect of environmental and chemotactic stimuli on the activity of the Campylobacter jejuni flaA sigma (28) promoter. FEMS Microbiol. Lett. 205, 43-48. doi: 10.1016/s0378-1097(01)00 444-x

Amerah, A. M., Mathis, G., and Hofacre, C. L. (2012). Effect of xylanase and a blend of essential oils on performance and Salmonella colonization of broiler chickens challenged with Salmonella Heidelberg. Poult. Sci. 91, 943-947. doi: 10.3382/ps.2011-01922

Anand, S., Kaur, H., and Mande, S. S. (2016). Comparative in silico analysis of butyrate production pathways in gut commensals and pathogens. Front. Microbiol. 7:1945. doi: 10.3389/fmicb.2016.01945

Anderson, R. C., Krueger, N. A., Byrd, J. A., Harvey, R. B., Callaway, T. R., Edrington, T. S., et al. (2009). Effects of thymol and diphenyliodonium chloride 
against Campylobacter spp. during pure and mixed culture in vitro. J. Appl. Microbiol. 107, 1258-1268. doi: 10.1111/j.1365-2672.2009.04308.x

Ansari-Lari, M., Hosseinzadeh, S., Shekarforoush, S. S., Abdollahi, M., and Berizi, E. (2011). Prevalence and risk factors associated with Campylobacter infections in broiler flocks in Shiraz, southern Iran. Int. J. Food Microbiol. 144, 475-479. doi: 10.1016/j.ijfoodmicro.2010.11.003

Arsi, K., Donoghue, A. M., Venkitanarayanan, K., Kollanoor-Johny, A., Fanatico, A. C., Blore, P. J., et al. (2014). The efficacy of the natural plant extracts, thymol and carvacrol against Campylobacter colonization in broiler chickens. J. Food Saf. 34, 321-325. doi: 10.1111/jfs.12129

Aslim, B., and Yucel, N. (2008). In vitro antimicrobial activity of essential oil from endemic Origanum minutiflorum on ciprofloxacin-resistant Campylobacter spp. Food Chem. 107, 602-606. doi: 10.1016/j.foodchem.2007.08.048

Austgulen, L. T., Solheim, E., and Schelin, R. R. (1987). Metabolism in rats of p-cymene derivates: carvacrol and thymol. Pharmacol. Toxicol. 61, 98-102. doi: 10.1111/j.1600-0773.1987.tb01783.x

Awad, W. A., Hess, C., and Hess, M. (2018). Re-thinking the chickenCampylobacter jejuni interaction: a review. Avian Pathol. 47, 352-363. doi: 10.1080/03079457.2018.1475724

Bajpai, V. K., Baek, K.-H., and Kang, S. C. (2012). Control of Salmonella in foods by using essential oils: a review. Food Res. Int. 45, 722-734. doi: 10.1016/j.foodres.2011.04.052

Bakkali, F., Averbeck, S., Averbeck, D., and Idaomar, M. (2008). Biological effects of essential oils: a review. Food Chem. Toxicol. 46, 446-475.

Bansil, R., and Turner, B. S. (2006). Mucin structure, aggregation, physiological functions and biomedical applications. Curr. Opin. Colloid Interface Sci. 11, 164-170. doi: 10.1016/j.cocis.2005.11.001

Bansode, S. S., Banarjee, S. K., Gaikwad, D. D., Jadhav, S. L., and Thorat, R. M. (2010). Microencapsulation: a review. Int. J. Pharm. Sci. Rev. Res. 1, 38-43.

Baratta, M. T., Dorman, H. D., Deans, S. G., Figueiredo, A. C., Barroso, J. G., and Ruberto, G. (1998). Antimicrobial and antioxidant properties of some commercial essential oils. Flavour Fragr. J. 13, 235-244. doi: 10.1002/(sici) 1099-1026(1998070)13\%3A4\%3C235\%3A\%3Aaid-ffj733\%3E3.3.co\%3B2-k

Bashor, M. P., Curtis, P. A., Keener, K. M., Sheldon, B. W., Kathariou, S., and Osborne, J. A. (2004). Effects of carcass washers on Campylobacter contamination in large broiler processing plants. Poult. Sci. 83, 1232-1239. doi: $10.1093 / \mathrm{ps} / 83.7 .1232$

Basmacioğlu Malayoğlu, H., Baysal, Ş., Misirlioğlu, Z., Polat, M., Yilmaz, H., and Turan, N. (2010). Effects of oregano essential oil with or without feed enzymes on growth performance, digestive enzyme, nutrient digestibility, lipid metabolism and immune response of broilers fed on wheat-soybean meal diets. Br. Poult. Sci. 51, 67-80. doi: 10.1080/00071660903573702

Batz, M. B., Hoffmann, S., and Morris, J. G. Jr. (2012). Ranking the disease burden of 14 pathogens in food sources in the United States using attribution data from outbreak investigations and expert elicitation. J. Food Prot. 75, 1278-1291. doi: 10.4315/0362-028X.JFP-11-418

Baurhoo, B., Ruiz-Feria, C. A., and Zhao, X. (2008). Purified lignin: nutritional and health impacts on farm animals-A review. Anim. Feed Sci. Technol. 144, 175-184. doi: 10.1016/j.anifeedsci.2007.10.016

Beery, J. T., Hugdahl, M. B., and Doyle, M. P. (1988). Colonization of gastrointestinal tracts of chicks by Campylobacter jejuni. Appl. Environ. Microbiol. 54, 2365-2370.

Benavides, S., Villalobos-Carvajal, R., and Reyes, J. E. (2012). Physical, mechanical and antibacterial properties of alginate film: effect of the crosslinking degree and oregano essential oil concentration. J. Food Eng. 110, 232-239. doi: 10.1016/j. jfoodeng.2011.05.023

Bengmark, S. (1998). Immunonutrition: role of biosurfactants, fiber, and probiotic bacteria. Nutrition 14, 585-594. doi: 10.1016/s0899-9007(98)00030-6

Berrang, M. E., Buhr, R. J., Cason, J. A., and Dickens, J. A. (2001). Broiler carcass contamination with Campylobacter from feces during defeathering. J. Food Prot. 64, 2063-2066. doi: 10.4315/0362-028x-64.12.2063

Bolton, D. J. (2015). Campylobacter virulence and survival factors. Food Microbiol. 48, 99-108. doi: 10.1016/j.fm.2014.11.017

Bozkurt, M., Küçükyilmaz, K., Catli, A. U., Çınar, M., Bintaş, E., and Çöven, F. (2012). Performance, egg quality, and immune response of laying hens fed diets supplemented with mannan-oligosaccharide or an essential oil mixture under moderate and hot environmental conditions. Poult. Sci. 91, 1379-1386. doi: 10.3382/ps.2011-02023
Brenes, A., and Roura, E. (2010). Essential oils in poultry nutrition: main effects and modes of action. Anim. Feed Sci. Technol. 158, 1-14. doi: 10.1016/j.anifeedsci. 2010.03.007

Buchbauer, G., Jirovetz, L., and Jäger, W. (1991). Aromatherapy: evidence for sedative effects of the essential oil of lavender after inhalation. Z. Naturforsch. C 46, 1067-1072. doi: 10.1515/znc-1991-11-1223

Burt, S. (2004). Essential oils: their antibacterial properties and potential applications in foods-a review. Int. J. Food Microbiol. 94, 223-253. doi: 10. 1016/j.ijfoodmicro.2004.03.022

Cabuk, M., Bozkurt, M., Alcicek, A., Akbap, Y., and Küçükyýlmaz, K. (2006). Effect of a herbal essential oil mixture on growth and internal organ weight of broilers from young and old breeder flocks. S. Afr. J. Anim. Sci. 36, 135-141.

Callaway, T. R., Carroll, J. A., Arthington, J. D., Edrington, T. S., Anderson, R. C., Ricke, S. C., et al. (2011). "Citrus products and their use against bacteria: potential health and cost benefits," in Nutrients, Dietary Supplements, and Nutriceuticals, eds R. R. Watson, J. K. Gerald, and V. R. Preedy (New York, NY: Humana Press), 277-286. doi: 10.1007/978-1-60761-308-4_17

Callicott, K. A., Friðriksdóttir, V., Reiersen, J., Lowman, R., Bisaillon, J. R., Gunnarsson, E., et al. (2006). Lack of evidence for vertical transmission of Campylobacter spp. in chickens. Appl. Environ. Microbiol. 72, 5794-5798. doi: 10.1128/aem.02991-05

Calo, J. R., Crandall, P. G., O’Bryan, C. A., and Ricke, S. C. (2015). Essential oils as antimicrobials in food systems-A review. Food Control 54, 111-119. doi: 10.1016/j.foodcont.2014.12.040

Carocho, M., Barreiro, M. F., Morales, P., and Ferreira, I. C. (2014). Adding molecules to food, pros and cons: a review on synthetic and natural food additives. Compr. Rev. Food Sci. Food Saf. 13, 377-399. doi: 10.1111/1541-4337. 12065

Carson, C. F., Mee, B. J., and Riley, T. V. (2002). Mechanism of action of Melaleuca alternifolia (tea tree) oil on Staphylococcus aureus determined by time-kill, lysis, leakage, and salt tolerance assays and electron microscopy. Antimicrob. Agents Chemother. 46, 1914-1920. doi: 10.1128/aac.46.6.1914-1920.2002

Caspi, R., Billington, R., Ferrer, L., Foerster, H., Fulcher, C. A., Keseler, I. M., et al. (2015). The MetaCyc database of metabolic pathways and enzymes and the BioCyc collection of pathway/genome databases. Nucleic Acids Res. 44, D471-D480. doi: 10.1093/nar/gkv1164

Centers for Disease Control and Prevention [CDC] (2017a). Foodborne Diseases Active Surveillance Network (FoodNet): FoodNet 2015 Surveillance Report (Final Data). Atlanta, GA: U.S. Department of Health and Human Services.

Centers for Disease Control and Prevention [CDC] (2017b). Reports of Selected Campylobacter Outbreak Investigations.

Centers for Disease Control and Prevention [CDC] (2018). Campylobacter (Campylobacteriosis).

Cervantes, H. M. (2015). Antibiotic-free poultry production: is it sustainable? J. Appl. Poult. Res. 24, 91-97. doi: 10.3382/japr/pfv006

Chalova, V. I., Crandall, P. G., and Ricke, S. C. (2010). Microbial inhibitory and radical scavenging activities of cold-pressed terpeneless Valencia orange (Citrus sinensis) oil in different dispersing agents. J. Sci. Food Agric. 90, 870-876. doi: $10.1002 /$ jsfa. 3897

Chang, M. H., and Chen, T. C. (2000). Reduction of Campylobacter jejuni in a simulated chicken digestive tract by lactobacilli cultures. J. Food Prot. 63, 1594-1597. doi: 10.4315/0362-028x-63.11.1594

Chapman, B., Otten, A., Fazil, A., Ernst, N., and Smith, B. A. (2016). A review of quantitative microbial risk assessment and consumer process models for Campylobacter in broiler chickens. Microb. Risk Anal. 2, 3-15. doi: 10.1016/ j.mran.2016.07.001

Chaveerach, P., Lipman, L. J. A., and Van Knapen, F. (2004). Antagonistic activities of several bacteria on in vitro growth of 10 strains of Campylobacter jejuni/coli. Int. J. Food Microbiol. 90, 43-50. doi: 10.1016/s0168-1605(03)00170-3

Chouliara, E., Karatapanis, A., Savvaidis, I. N., and Kontominas, M. G. (2007). Combined effect of oregano essential oil and modified atmosphere packaging on shelf-life extension of fresh chicken breast meat, stored at 4 C. Food Microbiol. 24, 607-617. doi: 10.1016/j.fm.2006.12.005

Chuma, T., Yamada, T., Yano, K., Okamoto, K., and Yugi, H. (1994). A survey of Campylobacter jejuni in broilers from assignment to slaughter using DNA-DNA hybridization. J. Vet. Med. Sci. 56, 697-700. doi: 10.1292/jvms. 56.697 
Clark, A. G., and Bueschkens, D. H. (1985). Laboratory infection of chicken eggs with Campylobacter jejuni by using temperature or pressure differentials. Appl. Environ. Microbiol. 49, 1467-1471.

Connerton, P. L., Richards, P. J., Lafontaine, G. M., O’Kane, P. M., Ghaffar, N., Cummings, N. J., et al. (2018). The effect of the timing of exposure to Campylobacter jejuni on the gut microbiome and inflammatory responses of broiler chickens. Microbiome 6:88. doi: 10.1186/s40168-018-0477-5

Corcionivoschi, N., Alvarez, L. A., Sharp, T. H., Strengert, M., Alemka, A., Mantell, J., et al. (2012). Mucosal reactive oxygen species decrease virulence by disrupting Campylobacter jejuni phosphotyrosine signaling. Cell Host Microbe 12, 47-59. doi: 10.1016/j.chom.2012.05.018

Corry, J. E. L., and Atabay, H. I. (2001). Poultry as a source of Campylobacter and related organisms. J. Appl. Microbiol. 90, 96S-114S.

Cosentino, S., Tuberoso, C. I. G., Pisano, B., Satta, M. L., Mascia, V., Arzedi, E., et al. (1999). In-vitro antimicrobial activity and chemical composition of Sardinian Thymus essential oils. Lett. Appl. Microbiol. 29, 130-135. doi: 10.1046/j.1472765x.1999.00605.x

Costerton, J. W. (1995). Overview of microbial biofilms. J. Ind. Microbiol. 15, 137-140. doi: 10.1007/bf01569816

Cox, N. A., Richardson, L. J., Buhr, R. J., and Fedorka-Cray, P. J. (2010). Campylobacter can Remain in Various Organs - WorldPoultry.net.

Dang, S., Sun, L., Huang, Y., Lu, F., Liu, Y., Gong, H., et al. (2010). Structure of a fucose transporter in an outward-open conformation. Nature 467, 734-738. doi: 10.1038/nature09406

Davis, L., and DiRita, V. (2017). Growth and laboratory maintenance of Campylobacter jejuni. Curr. Protoc. Microbiol. 10, 8A.1.1-8A.1.7. doi: 10.1002/ 9780471729259.mc08a01s10

De Cesare, A., Sheldon, B. W., Smith, K. S., and Jykus, L. A. (2003). Survival and persistence of Campylobacter and Salmonella species under varying organic loads on food contact surfaces. J. Food Prot. 66, 1587-1594. doi: 10.4315/0362$028 \mathrm{x}-66.9 .1587$

De Sousa, J. P., de Araújo Torres, R., de Azerêdo, G. A., Figueiredo, R. C., da Silva Vasconcelos, M. A., and de Souza, E. L. (2012). Carvacrol and 1, 8cineole alone or in combination at sublethal concentrations induce changes in the cell morphology and membrane permeability of Pseudomonas fluorescens in a vegetable-based broth. Int. J. Food Microbiol. 158, 9-13. doi: 10.1016/j. ijfoodmicro.2012.06.008

Deborde, M., and Von Gunten, U. R. S. (2008). Reactions of chlorine with inorganic and organic compounds during water treatment-kinetics and mechanisms: a critical review. Water Res. 42, 13-51. doi: 10.1016/j.watres.2007.07.025

Debruyne, L., Gevers, D., and Vandamme, P. (2008). "Taxonomy of the Family Campylobacteraceae," in Campylobacter, 3rd Edn, eds I. Nachamkin, C. Szymanski, and M. Blaser (Washington, DC: ASM Press), 3-25. doi: 10.1128/ 9781555815554.ch1

Delaquis, P. J., Stanich, K., Girard, B., and Mazza, G. (2002). Antimicrobial activity of individual and mixed fractions of dill, cilantro, coriander and eucalyptus essential oils. Int. J. Food Microbiol. 74, 101-109. doi: 10.1016/s0168-1605(01) 00734-6

Demir, E., Sarica, S., Ozcan, M. A., and Suicmez, M. (2005). The use of natural feed additives as alternatives to an antibiotic growth promoter in broiler diets. Arch. Geflugelkunde 69, 110-116.

Denli, M., Okan, F., and Uluocak, A. N. (2004). Effect of dietary supplementation of herb essential oils on the growth performance, carcass and intestinal characteristics of quail (Coturnix coturnix japonica). S. Afr. J. Anim. Sci. 34, 174-179.

Di Pasqua, R., Mamone, G., Ferranti, P., Ercolini, D., and Mauriello, G. (2010). Changes in the proteome of Salmonella enterica serovar Thompson as stress adaptation to sublethal concentrations of thymol. Proteomics 10, 1040-1049. doi: 10.1002/pmic. 200900568

Diaz-Sanchez, S., D’Souza, D., Biswas, D., and Hanning, I. (2015). Botanical alternatives to antibiotics for use in organic poultry production. Poult. Sci. 94, 1419-1430. doi: 10.3382/ps/pev014

Diener, M., Helmle-Kolb, C., Murer, H., and Scharrer, E. (1993). Effect of shortchain fatty acids on cell volume and intracellular $\mathrm{pH}$ in rat distal colon. Pflügers Arch. 424, 216-223. doi: 10.1007/bf00384345

Dima, C., and Dima, S. (2015). Essential oils in foods: extraction, stabilization, and toxicity. Curr. Opin. Food Sci. 5, 29-35. doi: 10.1016/j.tplants.2016.10.005
Dittoe, D. K., Ricke, S. C., and Kiess, A. S. (2018). Organic acids and potential for modifying the avian gastrointestinal tract and reducing pathogens and disease. Front. Vet. Sci. 5:216. doi: 10.3389/fvets.2018.00216

Díaz, E., Ferrández, A., Prieto, M. A., and García, J. L. (2001). Biodegradation of aromatic compounds by Escherichia coli. Microbiol. Mol. Biol. Rev. 65, 523-569. doi: 10.1128/mmbr.65.4.523-569.2001

Djenane, D., Yangueela, J., Gomez, D., and Roncales, P. (2012). perspectives on the use of essential oils as antimicrobials against Campylobacter jejuni CECT 7572 in retail chicken meats packaged in microaerobic atmosphere. J. Food Saf. 32, 37-47. doi: 10.1111/j.1745-4565.2011.00342.x

Donlan, R. M., and Costerton, J. W. (2002). Biofilms: survival mechanisms of clinically relevant microorganisms. Clin. Microbiol. Rev. 15, 167-193. doi: $10.1128 / \mathrm{cmr}$.15.2.167-193.2002

Donsi, F., Annunziata, M., Sessa, M., and Ferrari, G. (2011). Nanoencapsulation of essential oils to enhance their antimicrobial activity in foods. LWT Food Sci. Technol. 44, 1908-1914. doi: 10.1016/j.foodchem.2018. 11.078

Duarte, A., Luís, Â., Oleastro, M., and Domingues, F. C. (2016). Antioxidant properties of coriander essential oil and linalool and their potential to control Campylobacter spp. Food Control 61, 115-122. doi: 10.1016/j.foodcont.2015. 09.033

Duarte, A., Martinho, A., Luís, A., Figueiras, A., Oleastro, M., Domingues, F. C., et al. (2015). Resveratrol encapsulation with methyl-b-cyclodextrin for antibacterial and antioxidant delivery applications. LWT Food Sci. Technol. 63, 1254-1260. doi: 10.1016/j.lwt.2015.04.004

Duke, G. E. (1986). “Alimentary canal: anatomy, regulation of feed, and motility," in Avian Physiology, ed. P. D. Sturkie (New York, NY: Springer-Verlag), 269302.

Dunkley, K. D., Dunkley, C. S., Njongmeta, N. L., Callaway, T. R., Hume, M. E., Kubena, L. F., et al. (2007). Comparison of in vitro fermentation and molecular microbial profiles of high-fiber feed substrates incubated with chicken cecal inocula. Poult. Sci. 86, 801-810. doi: $10.1093 / \mathrm{ps} / 86.5 .801$

Economou, K. D., Oreopoulou, V., and Thomopoulos, C. D. (1991). Antioxidant activity of some plant extracts of the family Labiatae. J. Am. Oil Chem. Soc. 68, 109-113. doi: 10.1007/bf02662329

Edris, A. E. (2007). Pharmaceutical and therapeutic potentials of essential oils and their individual volatile constituents: a review. Phytother. Res. 21, 308-323. doi: $10.1002 /$ ptr.2072

Eeckhaut, V., Van Immerseel, F., Dewulf, J., Pasmans, F., Haesebrouck, F., Ducatelle, R., et al. (2008). Arabinoxylooligosaccharides from wheat bran inhibit Salmonella colonization in broiler chickens. Poult. Sci. 87, 2329-2334. doi: 10.3382/ps.2008-00193

Elgayyar, M., Draughon, F. A., Golden, D. A., and Mount, J. R. (2001). Antimicrobial activity of essential oils from plants against selected pathogenic and saprophytic microorganisms. J. Food Prot. 64, 1019-1024. doi: 10.4315/ 0362-028x-64.7.1019

Emami, N. K., Samie, A., Rahmani, H. R., and Ruiz-Feria, C. A. (2012). The effect of peppermint essential oil and fructooligosaccharides, as alternatives to virginiamycin, on growth performance, digestibility, gut morphology and immune response of male broilers. Anim. Feed Sci. Technol. 175, 57-64. doi: 10.1016/j.anifeedsci.2012.04.001

Epps, S. V., Harvey, R. B., Byrd, J. A., Petrujkiæ, B. T., Sedej, I., Beier, R. C., et al. (2015). Comparative effect of thymol or its glucose conjugate, thymol- $\beta-D$ glucopyranoside, on Campylobacter in avian gut contents. J. Environ. Sci. Health Part B 50, 55-61. doi: 10.1080/03601234.2015.965634

European Food Safety Authority [EFSA] (2010). Scientific opinion on quantification of the risk posed by broiler meat to human campylobacteriosis in the EU. EFSA J. 8:1437. doi: 10.2903/j.efsa.2010.1437

Evans, W. C., and Fuchs, G. (1988). Anaerobic degradation of aromatic compounds. Annu. Rev. Microbiol. 42, 289-317. doi: 10.1146/annurev.micro. 42.1.289

Fabricant, F. (2008). Earl Grey Flavor, to Serve after Teatime. New York, NY: New York Times, D2.

Facciolà, A., Riso, R., Avventuroso, E., Visalli, G., Delia, S. A., and Laganà, P. (2017). Campylobacter: from microbiology to prevention. J. Prev. Med. Hyg. 58:E79.

Fenton, W. A., and Horwich, A. L. (1997). GroEL mediated protein folding. Prot. Sci. 6, 743-760. doi: 10.1002/pro.5560060401 
Fisher, K., and Phillips, C. (2008). Potential antimicrobial uses of essential oils in food: is citrus the answer? Trends Food Sci. Technol. 19, 156-164. doi: $10.1016 /$ j.tifs.2007.11.006

Fisher, K., and Phillips, C. (2009). The mechanism of action of a citrus oil blend against Enterococcus faecium and Enterococcus faecalis. J. Appl. Microbiol. 106, 1343-1349. doi: 10.1111/j.1365-2672.2008.04102.x

Fisher, K., and Phillips, C. A. (2006). The effect of lemon, orange and bergamot essential oils and their components on the survival of Campylobacter jejuni, Escherichia coli O157, Listeria monocytogenes, Bacillus cereus and Staphylococcus aureus in vitro and in food systems. J. Appl. Microbiol. 101, 1232-1240. doi: 10.1111/j.1365-2672.2006.03035.x

Fitzgerald, C., and Nachamkin, I. (2011). "Campylobacter and Arcobacter," in Manual of Clinical Microbiology, eds J. Versalovic, K. Carroll, G. Funke, J. Jorgensen, M. L. Landry, and D. W. Warnock (Washington, DC: ASM Press), 885-899.

Frank, J. F., Ehlers, J., and Wicker, L. (2003). Removal of Listeria monocytogenes and poultry soil-containing biofilms using chemical cleaning and sanitizing agents under static conditions. Food Prot. Trends 23, 654-663.

Franz, C., Baser, K. H. C., and Windisch, W. (2010). Essential oils and aromatic plants in animal feeding-a European perspective. A review. Flavour Fragr. J. 25, 327-340. doi: 10.1002/ffj. 1967

Frazer, A. C. (1994). "O-demethylation and other transformations of aromatic compounds by acetogenic bacteria," in Acetogenesis, ed. H. L. Drake (Boston, MA: Springer), 445-483. doi: 10.1007/978-1-4615-1777-1_17

Friedman, C. R., Hoekstra, R. M., Samuel, M., Marcus, R., Bender, J., Shiferaw, B., et al. (2004). Risk factors for sporadic Campylobacter infection in the United States: a case-control study in FoodNet sites. Clin. Infect. Dis. 38(Suppl._3), S285-S296.

Friedman, M., Henika, P. R., and Mandrell, R. E. (2002). Bactericidal activities of plant essential oils and some of their isolated constituents against Campylobacter jejuni, Escherichia coli, Listeria monocytogenes, and Salmonella enterica. J. Food Prot. 65, 1545-1560. doi: 10.4315/0362-028x-65. 10.1545

Gangaiah, D., Liu, Z., Arcos, J., Kassem, I. I., Sanad, Y., Torrelles, J. B., et al. (2010). Polyphosphate kinase 2: a novel determinant of stress responses and pathogenesis in Campylobacter jejuni. PLoS One 5:e12142. doi: 10.1371/journal. pone. 0012142

Garénaux, A., Jugiau, F., Rama, F., De Jonge, R., Denis, M., Federighi, M., et al. (2008). Survival of Campylobacter jejuni strains from different origins under oxidative stress conditions: effect of temperature. Curr. Microbiol. 56, 293-297. doi: $10.1007 / \mathrm{s} 00284-007-9082-8$

Geissler, C., and Powers, H. (2011). "Chapter 3: food safety," in Human Nutrition, 12th Edn, eds C. Geissler and H. Powers (Philadelphia, PA: Churchill Livingstone Elsevier), 51-68.

Gerwe, T., Bouma, A., Wagenaar, J. A., Jacobs-Reitsma, W. F., and Stegeman, A. (2010). Comparison of Campylobacter levels in crops and ceca of broilers at slaughter. Avian Dis. 54, 1072-1074. doi: 10.1637/9113-101809-resnote.1

Gongqiao, X. U., Khatri, I. A., Wang, R., Rahman, S., and Forstner, J. F. (2003). $\mathrm{N}$-linked oligosaccharides play a role in disulphide-dependent dimerization of intestinal mucin Muc2. Biochem. J. 373, 893-900. doi: 10.1042/bj2003 0096

Gonzalez-Molina, E., Moreno, D. A., and Garcia-Viguera, C. (2009). A new drink rich in healthy bioactives combining lemon and pomegranate juices. Food Chem. 115, 1364-1372. doi: 10.1016/j.foodchem.2009.01.056

Gous, R. M. (2010). Nutritional limitations on growth and development in poultry. Livest. Sci. 130, 25-32. doi: 10.1016/j.livsci.2010.02.007

Gracia, M. I., Millan, C., Sanchez, J., Guyard-Nicodeme, M., Mayot, J., Carre, Y., et al. (2015). Efficacy of feed additives against Campylobacter in live broilers during the entire rearing period: part B. Poult. Sci. 95, 886-892. doi: 10.3382/ ps/pev346

Grand View Research (2018). Essential Oils Market Size, Share \& Trends Analysis Report By Product (Orange, Corn, Mint, Eucalyptus, Citronella, Pepper Mint, Lemon, Clove Leaf, Lime, Spearmint), By Application, And Segment Forecasts, $2018-2025$.

Grilli, E., Vitari, F., Domeneghini, C., Palmonari, A., Tosi, G., Fantinati, P., et al. (2013). Development of a feed additive to reduce caecal Campylobacter jejuni in broilers at slaughter age: from in vitro to in vivo, a proof of concept. J. Appl. Microbiol. 114, 308-317. doi: 10.1111/jam.12053
Guarner, F., and Malagelada, J. R. (2003). Gut flora in health and disease. Lancet 361, 512-519. doi: 10.1016/s0140-6736(03)12489-0

Guccione, E., Del Rocio Leon-Kempis, M., Pearson, B. M., Hitchin, E., Mulholland, F., van Diemen, P. M., et al. (2008). Amino acid-dependent growth of Campylobacter jejuni: key roles for aspartase (AspA) under microaerobic and oxygen-limited conditions and identification of AspB (Cj0762), essential for growth on glutamate. Mol. Microbiol. 69, 77-93. doi: 10.1111/j.1365-2958.2008. 06263.x

Guenther, E. (ed.). (1948). “The essential oils," in Essential Oils, (New York, NY: D. Van Nostrand), 8-52.

Guinoiseau, E., Luciani, A., Rossi, P. G., Quilichini, Y., Ternengo, S., Bradesi, P., et al. (2010). Cellular effects induced by Inula graveolens and Santolina corsica essential oils on Staphylococcus aureus. Eur. J. Clin. Microbiol. Infect. Dis. 29, 873-879. doi: 10.1007/s10096-010-0943-x

Gunther, N. W., and Chen, C. Y. (2009). The biofilm forming potential of bacterial species in the genus Campylobacter. Food Microbiol. 26, 44-51. doi: 10.1016/j. fm.2008.07.012

Guyard-Nicodeme, M., Keita, A., Quesne, S., Amelot, M., Poezevara, T., Le Berre, B., et al. (2015). Efficacy of feed additives against Campylobacter in live broilers during the entire rearing period. Poult. Sci. 95, 298-305. doi: 10.3382/ps/pev303

Häggblom, M. M., Rivera, M. D., and Young, L. Y. (1993). Influence of alternative electron acceptors on the anaerobic biodegradability of chlorinated phenols and benzoic acids. Appl. Environ. Microbiol. 59, 1162-1167.

Hajlaoui, H., Trabelsi, N., Noumi, E., Snoussi, M., Fallah, H., Ksouri, R., et al. (2009). Biological activities of the essential oils and methanol extract of two cultivated mint species (Mentha longifolia and Mentha pulegium) used in the Tunisian folkloric medicine. World J. Microbiol. Biotechnol. 25, 2227-2238. doi: 10.1007/s11274-009-0130-3

Hansen, A. K., Hansen, C. H. F., Krych, L., and Nielsen, D. S. (2014). Impact of the gut microbiota on rodent models of human disease. World J. Gastroenterol. 20:17727. doi: 10.3748 /wjg.v20.i47.17727

Hardin, A., Crandall, P. G., and Stankus, T. (2010). Essential oils and antioxidants derived from citrus by-products in food protection and medicine: an introduction and review of recent literature. J. Agric. Food Inf. 11, 99-122. doi: 10.1080/10496501003680680

Hardy, H., Harris, J., Lyon, E., Beal, J., and Foey, A. (2013). Probiotics, prebiotics and immunomodulation of gut mucosal defences: homeostasis and immunopathology. Nutrients 5, 1869-1912. doi: 10.3390/nu5061869

Hargis, B. M., Caldwell, D. J., Brewer, R. L., Corrier, D. E., and DeLoach, J. R. (1995). Evaluation of the chicken crop as a source of Salmonella contamination for broiler carcasses. Poult. Sci. 74, 1548-1552. doi: 10.3382/ps.0741548

Hazeleger, W., Wouters, J., Rombuts, F., and Abee, T. (1998). Physiological activity of Campylobacter jejuni far below the minimal growth temperature. Appl. Environ. Microbiol. 64, 3917-3922.

Helander, I. M., Alakomi, H. L., Latva-Kala, K., Mattila-Sandholm, T., Pol, I., Smid, E. J., et al. (1998). Characterization of the action of selected essential oil components on Gram-negative bacteria. J. Agric. Food Chem. 46, 3590-3595. doi: $10.1021 /$ jf980154m

Hermans, D., Martel, A., Van Deun, K., Verlinden, M., Van Immerseel, F., Garmyn, A., et al. (2010). Intestinal mucus protects Campylobacter jejuni in the ceca of colonized broiler chickens against the bactericidal effects of medium-chain fatty acids. Poult. Sci. 89, 1144-1155. doi: 10.3382/ps.201000717

Hermans, D., Pasmans, F., Heyndrickx, M., Van Immerseel, F., Martel, A., Van Deun, K., et al. (2012). A tolerogenic mucosal immune response leads to persistent Campylobacter jejuni colonization in the chicken gut. Crit. Rev. Microbiol. 38, 17-29. doi: 10.3109/1040841X.2011.615298

Hermans, D., Martel, A., Van Deun, K., Van Immerseel, F., Heyndrickx, M., Haesebrouck, F., et al. (2011a). The cinnamon-oil ingredient transcinnamaldehyde fails to target Campylobacter jejuni strain KC 40 in the broiler chicken cecum despite marked in vitro activity. J. Food Prot. 74, 1729-1734. doi: 10.4315/0362-028X.JFP-10-487

Hermans, D., Van Deun, K., Martel, A., Van Immerseel, F., Messens, W., Heyndrickx, M., et al. (2011b). Colonization factors of Campylobacter jejuni in the chicken gut. Vet. Res. 42:82. doi: 10.1186/1297-9716-42-82

Hernandez, F., Madrid, J., Garcia, V., Orengo, J., and Megias, M. D. (2004). Influence of two plant extracts on broilers performance, digestibility, and digestive organ size. Poult. Sci. 83, 169-174. doi: 10.1093/ps/83.2.169 
Hinton, A. (2006). Growth of Campylobacter in media supplemented with organic acids. J. Food Prot. 69, 34-38. doi: 10.4315/0362-028x-69.1.34

Hofreuter, D., Tsai, J., Watson, R. O., Novik, V., Altman, B., Benitez, M., et al. (2006). Unique features of a highly pathogenic Campylobacter jejuni strain. Infect. Immun. 74, 4694-4707. doi: 10.1128/iai.00210-06

Holley, R. A., and Patel, D. (2005). Improvement in shelf-life and safety of perishable foods by plant essential oils and smoke antimicrobials. Food Microbiol. 22, 273-292. doi: 10.1016/j.fm.2004.08.006

Hooper, L. V., Wong, M. H., Thelin, A., Hansson, L., Falk, P. G., and Gordon, J. I. (2001). Molecular analysis of commensal host-microbial relationships in the intestine. Science 291, 881-884. doi: 10.1126/science.291.55 05.881

Horrocks, S. M., Anderson, R. C., Nielsbet, D. J., and Ricke, S. C. (2009). Incidence and ecology of Campylobacter jejuni and coli in animals. Anaerobe 15, 18-25. doi: 10.1016/j.anaerobe.2008.09.001

Hue, O., Le Bouquin, S., Laisney, M. J., Allain, V., Lalande, F., Petetin, I., et al. (2010). Prevalence of and risk factors for Campylobacter spp. contamination of broiler chicken carcasses at the slaughterhouse. Food Microbiol. 27, 992-999. doi: 10.1016/j.fm.2010.06.004

Hugdahl, M. B., Beery, J. T., and Doyle, M. P. (1988). Chemotactic behavior of Campylobacter jejuni. Infect. Immun. 56, 1560-1566.

Hyldgaard, M., Mygind, T., and Meyer, R. L. (2012). Essential oils in food preservation: mode of action, synergies, and interactions with food matrix components. Front. Microbiol. 3:12. doi: 10.3389/fmicb.2012.00012

Indikova, I., Humphrey, T. J., and Hilbert, F. (2015). Survival with a helping hand: Campylobacter and microbiota. Front. Microbiol. 6:1266. doi: 10.3389/fmicb. 2015.01266

Jager, W. (2010). "Metabolism of terpenoids in animal models and humans," in Handbook of Essential Oils: Science, Technology, and Applications, eds K. H. C. Baser and G. Buchbauer (Boca Raton, FL: CRC Press), 209-235.

Jahrmann, R. (2007). Metabolismus von Monterpenen und Sesquiterpenen in Mensch und Sängetier: Bedeutung für die Pharmazeutische Praxis. MPharm. Diploma thesis, University of Vienna, Vienna.

Jamroz, D., Orda, J., Kamel, C., Wiliczkiewicz, A., Wertelecki, T., and Skorupinska, J. (2003). The influence of phytogenic extracts on performance, nutrient digestibility, carcass characteristics, and gut microbial status in broiler chickens. J. Anim. Feed Sci. 12, 583-596. doi: 10.22358/jafs/67752/2003

Jamroz, D., Wertelecki, T., Houszka, M., and Kamel, C. (2006). Influence of diet type on the inclusion of plant origin active substances on morphological and histochemical characteristics of the stomach and jejunum walls in chicken. J. Anim. Physiol. Anim. Nutr. 90, 255-268. doi: 10.1111/j.1439-0396.2005. 00603.x

Jang, I. S., Ko, Y. H., Kang, S. Y., and Lee, C. Y. (2007). Effect of a commercial essential oil on growth performance, digestive enzyme activity and intestinal microflora population in broiler chickens. Anim. Feed Sci. Technol. 134, 304-315. doi: 10.1016/j.anifeedsci.2006.06.009

Jang, I. S., Ko, Y. H., Yang, H. Y., Ha, J. S., Kim, J. Y., Kang, S. Y., et al. (2004). Influence of essential oil components on growth performance and the functional activity of the pancreas and small intestine in broiler chickens. Asian Australas. J. Anim. Sci. 17, 394-400. doi: 10.5713/ajas.2004.394

Jo, C., Kang, H. J., Lee, M., Lee, N. Y., and Byun, M. W. (2004). The antioxidative potential of lyophilized citrus peel extract in different meat model systems during storage at 20 C. J. Muscle Foods 15, 95-107. doi: 10.1111/j.1745-4573. 2004.tb00714.x

Johnson, L. P., Walton, G. E., Psichas, A., Frost, G. S., Gibson, G. R., and Barraclough, T. G. (2015). Prebiotics modulate the effects of antibiotics on gut microbial diversity and functioning in vitro. Nutrients 7, 4480-4497. doi: $10.3390 /$ nu7064480

Johnson, R. (2015). US-EU Poultry Dispute on the use of Pathogen Reduction Treatments (PRTs). Washington, DC: Congressional Research Service, $7-57$.

Józefiak, D., Rutkowski, A., and Martin, S. A. (2004). Carbohydrate fermentation in the avian ceca: a review. Anim. Feed Sci. Technol. 113, 1-15. doi: 10.1016/j. anifeedsci.2003.09.007

Juliano, C., Mattana, A., and Usai, M. (2000). Composition and in vitro antimicrobial activity of the essential oil of Thymus herba-barona Loisel growing wild in Sardinia. J. Essent. Oil Res. 12, 516-522. doi: 10.1080/10412905. 2000.9699578
Jung, H. G., and Fahey, G. C. Jr. (1983). Nutritional implications of phenolic monomers and lignin: a review 1. J. Anim. Sci. 57, 206-219. doi: 10.2527/ jas1983.571206x

Jyothi, S. S., Seethadevi, A., Prabha, K. S., Muthuprasanna, P., and Pavitra, P. (2012). Microencapsulation: a review. Int. J. Pharma Bio Sci. 3, 509-531.

Kaakoush, N. O., Sodhi, N., Chenu, J. W., Cox, J. M., Riordan, S. M., and Mitchell, H. M. (2014). The interplay between Campylobacter and Helicobacter species and other gastrointestinal microbiota of commercial broiler chickens. Gut Pathog. 6:18. doi: 10.1186/1757-4749-6-18

Kalchayanand, N., Dunne, P., Sikes, A., and Ray, B. (2004). Viability loss and morphology change of foodborne pathogens following exposure to hydrostatic pressures in the presence and absence of bacteriocins. Int. J. Food Microbiol. 91, 91-98. doi: 10.1016/s0168-1605(03)00324-6

Kassem, I. I., Chandrashekhar, K., and Rajashekara, G. (2013). Of energy and survival incognito: a relationship between viable but non-culturable cells formation and inorganic polyphosphate and formate metabolism in Campylobacter jejuni. Front. Microbiol. 4:183. doi: 10.3389/fmicb.2013.00183

Kavanaugh, N. L., and Ribbeck, K. (2012). Selected antimicrobial essential oils eradicate Pseudomonas spp. and Staphylococcus aureus biofilms. Appl. Environ. Microbiol. 78, 4057-4061. doi: 10.1128/AEM.07499-11

Keener, K. M., Bashor, M. P., Curtis, P. A., Sheldon, B. W., and Kathariou, S. (2004). Comprehensive review of Campylobacter and poultry processing. Compr. Rev. Food Sci. Food Saf. 3, 105-116. doi: 10.1111/j.1541-4337.2004.tb00060.x

Kelly, C., Gundogdu, O., Pircalabioru, G., Cean, A., Scates, P., Linton, M., et al. (2017). The in vitro and in vivo effect of carvacrol in preventing Campylobacter infection, colonization and in improving productivity of chicken broilers. Foodborne Pathog. Dis. 14, 341-349. doi: 10.1089/fpd.2016.2265

Kerekes, E. B., Vidács, A., Török Jenei, J., Gömöri, C., Takó, M., Chandrasekaran, M., et al. (2015). "Essential oils against bacterial biofilm formation and quorum sensing of food-borne pathogens and spoilage microorganisms," in The Battle Against Microbial Pathogens: Basic Science, Technological Advances and Educational Programs. Microbiology Book Series, Vol. 5, ed. A. Méndez-Vilas (Bajadoz: Formatex Research Center), 429-437.

Keto-Timonen, R., Hietala, N., Palonen, E., Hakakorpi, A., Lindström, M., and Korkeala, H. (2016). Cold shock proteins: a minireview with special emphasis on Csp-family of enteropathogenic Yersinia. Front. Microbiol. 7:1151. doi: 10. 3389/fmicb.2016.01151

Khan, I. A., and Abourashed, E. A. (2011). Leung's Encyclopedia of Common Natural Ingredients: Used in Food, Drugs and Cosmetics. Hoboken, NJ: John Wiley \& Sons.

Kirkpinar, F., Ünlü, H. B., Serdaroğlu, M., and Turp, G. Y. (2014). Effects of dietary oregano and garlic essential oils on carcass characteristics, meat composition, colour, $\mathrm{pH}$ and sensory quality of broiler meat. Br. Poult. Sci. 55, 157-166. doi: 10.1080/00071668.2013.879980

Kivanç, M., Akgül, A., and Dogan, A. (1991). Inhibitory and stimulatory effects of cumin, oregano and their essential oils on growth and acid production of Lactobacillus plantarum and Leuconostoc mesenteroides. Int. J. Food Microbiol. 13, 81-85. doi: 10.1016/0168-1605(91)90140-k

Klancnik, A., Guzej, B., Kolar, H. M., Abramovic, H., and Smole Mozina, S. (2009). In vitro antimicrobial and antioxidant activity of commercial rosemary extract formulations. J. Food Prot. 72, 1744-1752. doi: 10.4315/0362-028x-72.8.1744

Kohlert, C., Schindler, G., Marz, R. W., Abel, G., Brinkhaus, B., Derendorf, H., et al. (2002). Systemic availability and pharmacokinetics of thymol in humans. J. Clin. Pharmocol. 42, 731-737. doi: 10.1177/009127002401102678

Kollanoor-Johny, A., Darre, M. J., Donoghue, A. M., Donoghue, D. J., and Venkitanarayanan, K. (2010). Antibacterial effect of trans-cinnamaldehyde, eugenol, carvacrol, and thymol on Salmonella Enteritidis and Campylobacter jejuni in chicken cecal contents in vitro. J. Appl. Poult. Res. 19, 237-244. doi: 10.3382/japr.2010-00181

Konkel, M. E., Christensen, J. E., Keech, A. M., Monteville, M. R., Klena, J. D., and Garvis, S. G. (2005). Identification of a fibronectin-binding domain within the Campylobacter jejuni CadF protein. Mol. Microbiol. 57, 1022-1035. doi: 10.1111/j.1365-2958.2005.04744.x

Kostaki, M., Giatrakou, V., Savvaidis, I. N., and Kontominas, M. G. (2009). Combined effect of MAP and thyme essential oil on the microbiological, chemical and sensory attributes of organically aquacultured sea bass (Dicentrarchus labrax) fillets. Food Microbiol. 26, 475-482. doi: 10.1016/j.fm. 2009.02.008 
Koutsos, E. A., and Arias, V. J. (2006). Intestinal ecology: interactions among the gastrointestinal tract, nutrition, and the microflora. J. Appl. Poult. Res. 15, 161-173. doi: 10.1093/japr/15.1.161

Kreydiyyeh, S. I., Usta, J., and Copti, R. (2000). Effect of cinnamon, clove and some of their constituents on the Na+-K+-ATPase activity and alanine absorption in the rat jejunum. Food Chem. Toxicol. 38, 755-762. doi: 10.1016/s0278-6915(00) 00073-9

Kroismayr, A., Sehm, J., Pfaffl, M. W., Schedle, K., Plitzner, C., and Windisch, W. (2008). Effects of avilamycin and essential oils on mRNA expression of apoptotic and inflammatory markers and gut morphology of piglets. Czech J. Anim. Sci. 53, 377-387. doi: 10.17221/338-cjas

Kumar, J. K., Tabor, S., and Richardson, C. C. (2004). Proteomic analysis of thioredoxin-targeted proteins in Escherichia coli. Proc. Natl. Acad. Sci. U.S.A. 101, 3759-3764. doi: 10.1073/pnas.0308701101

Kurekci, C., Padmanabha, J., Bishop-Hurley, S. L., Hassan, E., Al Jassim, R. A., and McSweeney, C. S. (2013). Antimicrobial activity of essential oils and five terpenoid compounds against Campylobacter jejuni in pure and mixed culture experiments. Int. J. Food Microbiol. 166, 450-457. doi: 10.1016/j.ijfoodmicro. 2013.08.014

Kwon, J. A., Yu, C. B., and Park, H. D. (2003). Bacteriocidal effects and inhibition of cell separation of cinnamic aldehyde on Bacillus cereus. Lett. Appl. Microbiol. 37, 61-65. doi: 10.1046/j.1472-765x.2003.01350.x

Laanbroek, H. J., Kingma, W., and Veldkamp, H. (1977). Isolation of an aspartate fermenting, free-living Campylobacter species. FEMS Microbiol. Lett. 1, 99-102. doi: 10.1016/0378-1097(77)90010-6

Lambert, R. J. W., Skandamis, P. N., Coote, P. J., and Nychas, G. J. (2001). A study of the minimum inhibitory concentration and mode of action of oregano essential oil, thymol and carvacrol. J. Appl. Microbiol. 91, 453-462. doi: 10.1046/ j.1365-2672.2001.01428.x

Lee, H. W., Park, Y. S., Jung, J. S., and Shin, W. S. (2002). Chitosan oligosaccharides, dp 2-8, have prebiotic effect on the Bifidobacterium bifidum and Lactobacillus sp. Anaerobe 8, 319-324. doi: 10.1016/s1075-9964(03)00 030-1

Lee, K. W., Everts, H., and Beynen, A. (2004a). Essential oils in broiler nutrition. Int. J. Poult. Sci. 3, 738-752. doi: 10.3923/ijps.2004.738.752

Lee, K. W., Everts, H., Kappert, H. J., van Der Kuilen, J., Lemmens, A. G., Frehner, M., et al. (2004b). Growth performance, intestinal viscosity, fat digestibility and plasma cholesterol in broiler chickens fed a rye-containing diet without or with essential oil components. Int. J. Poult. Sci. 3, 613-618. doi: 10.3923/ijps.2004. 613.618

Lee, K. W., Everts, H., Kappert, H. J., Frehner, M., Losa, R., and Beynen, A. C. (2003). Effects of dietary essential oil components on growth performance, digestive enzymes and lipid metabolism in female broiler chickens. Br. Poult. Sci. 44, 450-457. doi: 10.1080/00071660301985

Leenstra, F. R. (1986). Effect of age, sex, genotype and environment on fat deposition in broiler chickens-a review. Worlds Poult. Sci. J. 42, 12-25. doi: $10.1079 /$ wps 19860002

Leistner, L. (2000). Basic aspects of food preservation by hurdle technology. Int. J. Food Microbiol. 55, 181-186. doi: 10.1016/s0168-1605(00)00161-6

Levin, R. E. (2007). Campylobacter jejuni: a review of its characteristics, pathogenicity, ecology, distribution, subspecies characterization and molecular methods of detection. Food Biotechnol. 21, 271-347. doi: 10.1080/ 08905430701536565

Lien, K. A., Sauer, W. C., and He, J. M. (2001). Dietary influences on the secretion into and degradation of mucin in the digestive tract of monogastric animals and humans. J. Anim. Feed Sci. 10, 223-246.

Lin, A. E., Krastel, K., Hobb, R. I., Thompson, S. A., Cvitkovitch, D. G., and Gaynor, E. C. (2009). Atypical roles for Campylobacter jejuni amino acid ATP binding cassette transporter components PaqP and PaqQ in bacterial stress tolerance and pathogen-host cell dynamics. Infect. Immunol. 77, 4912-4924. doi: 10.1128/IAI.00571-08

Line, J. E. (2001). Development of a selective differential agar for isolation and enumeration of Campylobacter spp. J. Food Prot. 64, 1711-1715. doi: 10.4315/ 0362-028x-64.11.1711

Line, J. E., Hiett, K. L., Guard-Bouldin, J., and Seal, B. S. (2010). Differential carbon source utilization by Campylobacter jejuni 11168 in response to growth temperature variation. J. Microbiol. Methods 80, 198-202. doi: 10.1016/j.mimet. 2009.12.011
Liu, S., Bennett, D. C., Tun, H. M., Kim, J. E., Cheng, K. M., Zhang, H., et al. (2015). The effect of diet and host genotype on ceca microbiota of Japanese quail fed a cholesterol enriched diet. Front. Microbiol. 6:1092. doi: 10.3389/fmicb.2015. 01092

Looft, T., Cai, G., Choudhury, B., Lai, L. X., Lippolis, J. D., Reinhardt, T. A., et al. (2019). Avian intestinal mucus modulates Campylobacter jejuni gene expression in a host-specific manner. Front. Microbiol. 9:3215. doi: 10.3389/fmicb.2018. 03215

Los Santos, F. S., Donoghue, A. M., Venkitanarayanan, K., Dirain, M. L., ReyesHerrera, I., Blore, P. J., et al. (2008). Caprylic acid supplemented in feed reduces enteric Campylobacter jejuni colonization in ten-day-old broiler chickens. Poult. Sci. 87, 800-804. doi: 10.3382/ps.2007-00280

Los Santos, F. S., Donoghue, A. M., Venkitanarayanan, K., Metcalf, J. H., ReyesHerrera, I., Dirain, M. L., et al. (2009). The natural feed additive caprylic acid decreases Campylobacter jejuni colonization in market-aged broiler chickens. Poult. Sci. 88, 61-64. doi: 10.3382/ps.2008-00228

Lourenço, M. C., Kuritza, L. N., Hayashi, R. M., Miglino, L. B., Durau, J. F., Pickler, L., et al. (2015). Effect of a mannanoligosaccharide-supplemented diet on intestinal mucosa $\mathrm{T}$ lymphocyte populations in chickens challenged with Salmonella Enteritidis. J. Appl. Poult. Res. 24, 15-22. doi: 10.3382/japr/pfu002

Mack, D. R., Michail, S., Wei, S., McDougall, L., and Hollingsworth, M. A. (1999). Probiotics inhibit enteropathogenic E. coli adherence in vitro by inducing intestinal mucin gene expression. Am. J. Physiol. 276, G941-G950. doi: 10.1152/ ajpgi.1999.276.4.G941

Manzanilla, E. G., Baucells, F., Kamel, C., Morales, J., Perez, J. F., and Gasa, J. (2001). Effects of plant extracts on the performance and lower gut microflora of early weaned piglets. J. Anim. Sci. 1:473. doi: 10.1111/jpn.12976

Manzanilla, E. G., Perez, J. F., Martin, M., Kamel, C., Baucells, F., and Gasa, J. (2004). Effect of plant extracts and formic acid on the intestinal equilibrium of early- weaned pigs. J. Anim. Sci. 82, 3210-3218. doi: 10.2527/2004.82113210x

Martucci, J. F., Gende, L. B., Neira, L. M., and Ruseckaite, R. A. (2015). Oregano and lavender essential oils as antioxidant and antimicrobial additives of biogenic gelatin films. Ind. Crops Prod. 71, 205-213. doi: 10.1016/j.indcrop.2015.03.079

Messaoudi, S., Kergourlay, G., Dalgalarrondo, M., Choiset, Y., Ferchichi, M., Prévost, H., et al. (2012). Purification and characterization of a new bacteriocin active against Campylobacter produced by Lactobacillus salivarius SMXD51. Food Microbiol. 32, 129-134. doi: 10.1016/j.fm.2012.05.002

Metcalf, J. H., Donoghue, A. M., Venkitanarayanan, K., Reyes-Herrera, I., Aguiar, V. F., Blore, P. J., et al. (2011). Water administration of the medium-chain fatty acid caprylic acid produced variable efficacy against enteric Campylobacter colonization in broilers. Poult. Sci. 90, 494-497. doi: 10.3382/ps.2010-00891

Meunier, J. P., Cardot, J. M., Gauthier, P., Beyssac, E., and Alric, M. (2006). Use of rotary fluidized-bed technology for development of sustained-release plant extracts pellets: potential application for feed additive delivery. J. Anim. Sci. 84, 1850-1859. doi: 10.2527/jas.2005-361

Micciche, A. C., Foley, S. L., Pavlidis, H. O., McIntyre, D. R., and Ricke, S. C. (2018a). A review of prebiotics against Salmonella in poultry: current and future potential for microbiome research applications. Front. Vet. Sci. 5:191. doi: $10.3389 /$ fvets.2018.00191

Micciche, A. C., Rubinelli, P. M., and Ricke, S. C. (2018b). Source of water and potential sanitizers and biological antimicrobials for alternative poultry processing food safety applications. Front. Sustain. Food Syst. 2:82. doi: 10.3389/ fsufs.2018.00082

Michiels, J., Missotten, J., Dierick, N., Fremaut, D., Maene, P., and De Smet, S. (2008). In vitro degradation and in vivo passage kinetics of carvacrol, thymol, eugenol and trans-cinnamaldehyde along the gastrointestinal tract of piglets. J. Sci. Food Agric. 88, 2371-2381. doi: 10.1002/jsfa.3358

Mohammadhosseini, M., Sarker, S. D., and Akbarzadeh, A. (2017). Chemical composition of the essential oils and extracts of Achillea species and their biological activities: a review. J. Ethnopharmacol. 199, 257-315. doi: 10.1016/ j.jep.2017.02.010

Moleyar, V., and Narasimham, P. (1992). Antibacterial activity of essential oil components. Int. J. Food Microbiol. 16, 337-342. doi: 10.1016/0168-1605(92) 90035-2

Montagne, L., Pluske, J. R., and Hampson, D. J. (2003). A review of interactions between dietary fibre and the intestinal mucosa, and their consequences on digestive health in young non-ruminant animals. Anim. Feed Sci. Technol. 108, 95-117. doi: 10.1016/s0377-8401(03)00163-9 
Monteville, M. R., Yoon, J. E., and Konkel, M. E. (2003). Maximal adherence and invasion of INT 407 cells by Campylobacter jejuni requires the CadF outer-membrane protein and microfilament reorganization. Microbiology 149, 153-165. doi: 10.1099/mic.0.25820-0

Montrose, M. S., Shane, S. M., and Harrington, K. S. (1985). Role of litter in the transmission of Campylobacter jejuni. Avian Dis. 29, 392-399.

Moreira, M. R., Ponce, A. G., Del Valle, C. E., and Roura, S. I. (2005). Inhibitory parameters of essential oils to reduce a foodborne pathogen. LWT Food Sci. Technol. 38, 565-570. doi: 10.1016/j.lwt.2004.07.012

Motojima, F. (2015). How do chaperonins fold protein? Biophysics 11, 93-102. doi: 10.2142/biophysics.11.93

Muraoka, W. T., and Zhang, Q. (2010). Phenotypic and genotypic evidence for L-fucose utilization by Campylobacter jejuni. J. Bacteriol. 193, 1065-1075. doi: 10.1128/JB.01252-10

Murray, C. J., Barber, R. M., Foreman, K. J., Ozgoren, A. A., Abd-Allah, F., Abera, S. F., et al. (2015). Global, regional, and national disability-adjusted life years (DALYs) for 306 diseases and injuries and healthy life expectancy (HALE) for 188 countries, 1990-2013: quantifying the epidemiological transition. Lancet 386, 2145-2191.

Nakatsu, T., Lupo, A. T. Jr., Chinn, J. W. Jr., and Kang, R. K. (2000). “Biological activity of essential oils and their constituents," in Studies in Natural Products Chemistry, Vol. 21, ed. A. Rahman (Amsterdam: Elsevier), 571-631. doi: 10. 1016/s1572-5995(00)80014-9

Namkung, H., Li, J., Gong, M., Yu, H., Cottrill, M., and De Lange, C. F. M. (2004). Impact of feeding blends of organic acids and herbal extracts on growth performance, gut microbiota and digestive function in newly weaned pigs. Can. J. Anim. Sci. 84, 697-704. doi: 10.4141/a04-005

Nannapaneni, R., Chalova, V. I., Crandall, P. G., Ricke, S. C., Johnson, M. G., and O'Bryan, C. A. (2009). Campylobacter and Arcobacter species sensitivity to commercial orange oil fractions. Int. J. Food Microbiol. 129, 43-49. doi: 10.1016/j.ijfoodmicro.2008.11.008

National Organic Program (2018). National Organic Program, 7 C.F.R. 205.601603.

Naughton, J. A., Mariño, K., Dolan, B., Reid, C., Gough, R., Gallagher, M. E., et al. (2013). Divergent mechanisms of interaction of Helicobacter pylori and Campylobacter jejuni with mucus and mucins. Infect. Immun. 81, 2838-2850. doi: 10.1128/IAI.00415-13

Nauta, M., Hill, A., Rosenquist, H., Brynestad, S., Fetsch, A., van der Logt, P., et al. (2009). A comparison of risk assessments on Campylobacter in broiler meat. Int. J. Food Microbiol. 129, 107-123. doi: 10.1016/j.ijfoodmicro.2008.12.001

Navarro, M., Stanley, R., Cusack, A., and Sultanbawa, Y. (2015). Combinations of plant-derived compounds against Campylobacter in vitro. J. Appl. Poult. Res. 24, 352-363. doi: 10.3382/japr/pfv035

Nazzaro, F., Fratianni, F., De Martino, L., Coppola, R., and De Feo, V. (2013). Effect of essential oils on pathogenic bacteria. Pharmaceuticals 6, 1451-1474. doi: 10.3390/ph6121451

Netzer, F., Kuntze, K., Vogt, C., Richnow, H. H., Boll, M., and Lueders, T. (2016). Functional gene markers for fumarate-adding and dearomatizing key enzymes in anaerobic aromatic hydrocarbon degradation in terrestrial environments. J. Mol. Microbiol. Biotechnol. 26, 180-194. doi: 10.1159/000441946

Nguefack, J., Tamgue, O., Dongmo, J. B. L., Dakole, C. D., Leth, V., Vismer, H. F., et al. (2012). Synergistic action between fractions of essential oils from Cymbopogon citratus, Ocimum gratissimum and Thymus vulgaris against Penicillium expansum. Food Control 23, 377-383. doi: 10.1016/j.foodcont.2011. 08.002

Nofrarias, M., Manzanilla, E. G., Pujols, J., Gibert, X., Majo, N., Segalés, J., et al. (2006). Effects of spray-dried porcine plasma and plant extracts on intestinal morphology and on leukocyte cell subsets of weaned pigs. J. Anim. Sci. 84, 2735-2742. doi: 10.2527/jas.2005-414

Oakley, B. B., Lillehoj, H. S., Kogut, M. H., Kim, W. K., Maurer, J. J., Pedroso, A., et al. (2014). The chicken gastrointestinal microbiome. FEMS Microbiol. Lett. 360, 100-112. doi: 10.1111/1574-6968.12608

O'Bryan, C. A., Crandall, P. G., Chalova, V. I., and Ricke, S. C. (2008). Orange essential oils antimicrobial activities against Salmonella spp. J. Food Sci. 73, M264-M267.

O'Bryan, C. A., Pendleton, S. J., Crandall, P. G., and Ricke, S. C. (2015). Potential of plant essential oils and their components in animal agriculture-in vitro studies on antibacterial mode of action. Front. Vet. Sci. 2:35. doi: 10.3389/fvets.2015. 00035

Overhage, J., Steinbuchel, A., and Priefert, H. (2003). Highly efficient Í biotransformation of eugenol to ferulic acid and further conversion to vanillin in recombinant strains of Escherichia coli. Appl. Environ. Microbiol. 69, 6569-6576.

Overhage, J., Steinbüchel, A., and Priefert, H. (2006). Harnessing eugenol as a substrate for production of aromatic compounds with recombinant strains of Amycolatopsis sp. HR167. J. Biotechnol. 125, 369-376. doi: 10.1016/j.jbiotec. 2006.03.024

Oyen, L. P. A., and Dung, N. X. (1999). “Essential-oil plants," in Plant Resources of South East Asia, eds L. P. A. Oyen and N. X. Dung (Leiden: Backhuys Publishers), 15-49.

Özek, K., Wellmann, K. T., Ertekin, B., and Tarım, B. (2011). Effects of dietary herbal essential oil mixture and organic acid preparation on laying traits, gastrointestinal tract characteristics, blood parameters and immune response of laying hens in a hot summer season. J. Anim. Feed Sci. 20, 575-586. doi: $10.22358 /$ jafs/66216/2011

Pan, K., Chen, H., Davidson, P. M., and Zhong, Q. (2014). Thymol nanoencapsulated by sodium caseinate: physical and antilisterial properties. J. Agric. Food Chem. 62, 1649-1657. doi: 10.1021/jf4055402

Papatsiros, V. G., Katsoulos, P. D., Koutoulis, K. C., Karatzia, M., Dedousi, A., and Christodoulopoulos, G. (2013). Alternatives to antibiotics for farm animals. CAB Rev. 8, 1-15.

Parker, C. T., Miller, W. G., Horn, S. T., and Lastovica, A. J. (2007). Common genomic features of Campylobacter jejuni subsp. doylei strains distinguish them from C. jejuni subsp. jejuni. BMC Microbiol. 7:50. doi: 10.1186/1471-2180-7-50

Parker, C. T., Quiñones, B., Miller, W. G., Horn, S. T., and Mandrell, R. E. (2006). Comparative genomic analysis of Campylobacter jejuni strains reveals diversity due to genomic elements similar to those present in C. jejuni strain RM1221. J. Clin. Microbiol. 44, 4125-4135. doi: 10.1128/jcm.01231-06

Parkhill, J., Wren, B. W., Mungall, K., Ketley, J. M., Churcher, C., Basham, D., et al. (2000). The genome sequence of the food-borne pathogen Campylobacter jejuni reveals hypervariable sequences. Nature 403, 665-668. doi: 10.1038/3500 1088

Parsons, C. M. (1984). Influence of caecectomy and source of dietary fibre or starch on excretion of endogenous amino acids by laying hens. Br. J. Nutr. 51, 541-548.

Perez-Vilar, J., and Hill, R. L. (1999). The structure and assembly of secreted mucins. J. Biol. Chem. 274, 31751-31754. doi: 10.1074/jbc.274.45.31751

Phadtare, S., and Severinov, K. (2010). RNA remodeling and gene regulation by cold shock proteins. RNA Biol. 7, 788-795. doi: 10.4161/rna.7.6.13482

Piskernik, S., Klanènik, A., Riedel, C. T., Brøndsted, L., and Možina, S. S. (2011). Reduction of Campylobacter jejuni by natural antimicrobials in chicken meatrelated conditions. Food Control 22, 718-724. doi: 10.1016/j.foodcont.2010. 11.002

Piva, G., and Rossi, F. (1998). "Possible alternatives to the use of antibiotics as growth promoters: new additives," in Proceedings of the IFIF II Conference of Mixed-Feed Manufactures in the Mediterranean, Reus, 83-106.

Prior, R. L., and Cao, G. (2000). Analysis of botanicals and dietary supplements for antioxidant capacity: a review. J. AOAC Int. 83, 950-956.

Quaroni, A., Isselbacher, K. J., and Ruoslahti, E. (1978). Fibronectin synthesis by epithelial crypt cells of rat small intestine. Proc. Natl. Acad. Sci. U.S.A. 75, 5548-5552. doi: 10.1073/pnas.75.11.5548

Raut, J. S., and Karuppayil, S. M. (2014). A status review on the medicinal properties of essential oils. Ind. Crops Prod. 62, 250-264. doi: 10.1016/j.indcrop. 2014.05.055

Ravindran, V., and Bryden, W. L. (1999). Amino acid availability in poultryIn vitro and in vivo measurements. Aust. J. Agric. Res. 50, 889-908.

Ricke, S. C. (2003). The gastrointestinal tract ecology of Salmonella Enteritidis colonization in molting hens. Poult. Sci. 82, 1003-1007. doi: 10.1093/ps/82.6. 1003

Ricke, S. C. (2018). Impact of prebiotics on poultry production and food safety. Yale J. Biol. Med. 91, 151-159.

Ricke, S. C., Dunkley, C. S., and Durant, J. A. (2013). A review on development of novel strategies for controlling Salmonella Enteritidis colonization in laying hens: fiber-based molt diets. Poult. Sci. 92, 502-525. doi: 10.3382/ps.201202763 
Ricke, S. C., Van der Aar, P. J., Fahey, G. C. Jr., and Berger, L. L. (1982). Influence of dietary fibers on performance and fermentation characteristics of gut contents from growing chicks. Poult. Sci. 61, 1335-1343. doi: 10.3382/ps.0611335

Rimini, S., Petracci, M., and Smith, D. P. (2014). The use of thyme and orange essential oils blend to improve quality traits of marinated chicken meat. Poult. Sci. 93, 2096-2102. doi: 10.3382/ps.2013-03601

Robbe, C., Capon, C., Coddeville, B., and Michalski, J. C. (2004). Structural diversity and specific distribution of $\mathrm{O}$-glycans in normal human mucins along the intestinal tract. Biochem. J. 384, 307-316. doi: 10.1042/bj20040605

Rosenquist, H., Nielsen, N. L., Sommer, H. M., Norrung, B., and Christensen, B. B. (2003). Quantitative risk assessment of human campylobacteriosis associated with thermophilic Campylobacter species in chickens. Int. J. Food Microbiol. 83, 87-103. doi: 10.1016/s0168-1605(02)00317-3

Rossi, P. G., Bao, L., Luciani, A., Panighi, J., Desjobert, J. M., Costa, J., et al. (2007). (E)-Methylisoeugenol and elemicin: antibacterial components of Daucus carota L. essential oil against Campylobacter jejuni. J. Agric. Food Chem. 55, 7332-7336. doi: 10.1021/jf070674u

Roto, S. M., Rubinelli, P. M., and Ricke, S. C. (2015). An introduction to the avian gut microbiota and the effects of yeast-based prebiotic-type compounds as potential feed additives. Front. Vet. Sci. 2:28. doi: 10.3389/fvets.2015.00028

Ruberto, G., Baratta, M. T., Deans, S. G., and Dorman, H. D. (2000). Antioxidant and antimicrobial activity of Foeniculum vulgare and Crithmum maritimum essential oils. Planta Med. 66, 687-693. doi: 10.1055/s-2000-9773

Rubinchik, S., Seddon, A., and Karlyshev, A. V. (2012). Molecular mechanisms and biological role of Campylobacter jejuni attachment to host cells. Eur. J. Microbiol. Immunol. 2, 32-40. doi: 10.1556/EuJMI.2.2012.1.6

Ryu, J. H., and Beuchat, L. R. (2005). Biofilm formation by Escherichia coli O157: $\mathrm{H} 7$ on stainless steel: effect of exopolysaccharide and curli production on its resistance to chlorine. Appl. Environ. Microbiol. 71, 247-254. doi: 10.1128/aem. 71.1.247-254.2005

Sahin, O., Kassem, I. I., Shen, Z., Lin, J., Rajashekara, G., and Zhang, Q. (2015). Campylobacter in poultry: ecology and potential interventions. Avian Dis. 59, 185-200. doi: 10.1637/11072-032315-Review

Sanders, S. Q., Frank, J. F., and Arnold, J. W. (2008). Temperature and nutrient effects on Campylobacter jejuni attachment on multispecies biofilms on stainless steel. J. Food Prot. 71, 271-278. doi: 10.4315/0362-028x-71.2.271

Santini, C., Baffoni, L., Gaggia, F., Granata, M., Gasbarri, R., Di Gioia, D., et al. (2010). Characterization of probiotic strains: an application as feed additives in poultry against Campylobacter jejuni. Int. J. Food Microbiol. 141, S98-S108. doi: 10.1016/j.ijfoodmicro.2010.03.039

Scallan, E., Hoekstra, R. M., Mahon, B. E., Jones, T. F., and Griffin, P. M. (2015). An assessment of the human health impact of seven leading foodborne pathogens in the United States using disability adjusted life years. Epidemiol. Infect. 143, 2795-2804. doi: 10.1017/S0950268814003185

Scher, K., Romling, U., and Yaron, S. (2005). Effect of heat, acidification, and chlorination on Salmonella enterica serovar Typhimurium cells in a biofilm formed at the air-liquid interface. Appl. Environ. Microbiol. 71, 1163-1168. doi: 10.1128/aem.71.3.1163-1168.2005

Schets, F. M., Jacobs-Reitsma, W. F., van der Plaats, R. Q., Heer, L. K. D., van Hoek, A. H., Hamidjaja, R. A., et al. (2017). Prevalence and types of Campylobacter on poultry farms and in their direct environment. J. Water Health 15, 849-862. doi: $10.2166 /$ wh.2017.119

Sergeant, M. J., Constantinidou, C., Cogan, T. A., Bedford, M. R., Penn, C. W., and Pallen, M. J. (2014). Extensive microbial and functional diversity within the chicken cecal microbiome. PLoS One 9:e91941. doi: 10.1371/journal.pone. 0091941

Shin, E., Hong, H., Oh, Y., and Lee, Y. (2015). First report and molecular characterization of a Campylobacter jejuni isolate with extensive drug resistance from a travel-associated human case. Antimicrob. Agents Chemother. 59, 6670-6672. doi: 10.1128/aac.01395-15

Si, W., Gong, J., Tsao, R., Zhou, T., Yu, H., Poppe, C., et al. (2006). Antimicrobial activity of essential oils and structurally related synthetic food additives towards selected pathogenic and beneficial gut bacteria. J. Appl. Microbiol. 100, 296-305. doi: 10.1111/j.1365-2672.2005.02789.x

Sibanda, N., McKenna, A., Richmond, A., Ricke, S. C., Callaway, T., Stratakos, A. C., et al. (2018). A review of the effect of management practices on Campylobacter prevalence in poultry farms. Front. Microbiol. 9:2002. doi: 10. 3389/fmicb.2018.02002
Sikkema, J., de Bont, J. A., and Poolman, B. (1995). Mechanisms of membrane toxicity of hydrocarbons. Microbiol. Rev. 59, 201-222.

Silva, J., Leite, D., Fernandes, M., Mena, C., Gibbs, P. A., and Teixeira, P. (2011). Campylobacter spp. as a foodborne pathogen: a review. Front. Microbiol. 2:200. doi: $10.3389 /$ fmicb. 2011.00200

Sima, F., Stratakos, A. C., Ward, P., Linton, M., Kelly, C., Pinkerton, L., et al. (2018). A novel natural antimicrobial can reduce the in vitro and in vivo pathogenicity of T6SS positive Campylobacter jejuni and Campylobacter coli chicken isolates. Front. Microbiol. 9:2139. doi: 10.3389/fmicb.2018.02139

Skandamis, P., Koutsoumanis, K., Nychas, G. J. E., and Fasseas, K. (2001). Inhibition of oregano essential oil and EDTA on Escherichia coli O157: H7 [food hygiene]. Ital. J. Food Sci. 13:65.

Smithard, R. (2002). “Chapter 14: secondary plant metabolites in poultry nutrition," in Poultry Feedstuffs: Supply, Composition and Nutritive Value, eds J. M. McNab and K. N. Boorman (Wallingford, CT: CABI Publishing), 237-278. doi: 10. 1079/9780851994642.0237

Smith-Palmer, A., Stewart, J., and Fyfe, L. (1998). Antimicrobial properties of plant essential oils and essences against five important food-borne pathogens. Lett. Appl. Microbiol. 26, 118-122. doi: 10.1046/j.1472-765x.1998. 00303.x

Son, I., Englen, M. D., Berrang, M. E., Fedorka-Cray, P. J., and Harrison, M. A. (2007). Prevalence of Arcobacter and Campylobacter on broiler carcasses during processing. Int. J. Food Microbiol. 113, 16-22. doi: 10.1016/j.ijfoodmicro.2006. 06.033

Srey, S., Jahid, I. K., and Ha, S. D. (2013). Biofilm formation in food industries: a food safety concern. Food Control 31, 572-585. doi: 10.1016/j.foodcont.2012. 12.001

Stahl, M., Butcher, J., and Stintzi, A. (2012). Nutrient acquisition and metabolism by Campylobacter jejuni. Front. Cell. Infect. Microbiol. 2:5. doi: 10.3389/fcimb. 2012.00005

Stahl, M., Friis, L. M., Nothaft, H., Liu, X., Li, J., Szymanski, C. M., et al. (2011). Lfucose utilization provides Campylobacter jejuni with a competitive advantage. Proc. Natl. Acad. Sci. U.S.A. 108, 7194-7199. doi: 10.1073/pnas.101412 5108

Stanley, D., Hughes, R. J., and Moore, R. J. (2014). Microbiota of the chicken gastrointestinal tract: influence on health, productivity and disease. Appl. Microbiol. Biotechnol. 98, 4301-4310. doi: 10.1007/s00253-0145646-2

Stern, N. J. (2008). Salmonella species and Campylobacter jejuni cecal colonization model in broilers. Poult. Sci. 87, 2399-2403. doi: 10.3382/ps.2008-00140

Stern, N. J., Fedorka-Cray, P., Bailey, J. S., Cox, N. A., Craven, S. E., Hiett, K. L., et al. (2001). Distribution of Campylobacter spp. in selected US poultry production and processing operations. J. Food Prot. 64, 1705-1710. doi: 10.4315/0362028x-64.11.1705

Stern, N. J., Svetoch, E. A., Eruslanov, B. V., Perelygin, V. V., Mitsevich, E. V., Mitsevich, I. P., et al. (2006). Isolation of a Lactobacillus salivarius strain and purification of its bacteriocin, which is inhibitory to Campylobacter jejuni in the chicken gastrointestinal system. Antimicrob. Agents Chemother. 50, 3111-3116. doi: 10.1128/aac.00259-06

Szczepanski, S., and Lipski, A. (2014). Essential oils show specific inhibiting effects on bacterial biofilm formation. Food Control 36, 224-229. doi: 10.1016/j. foodcont.2013.08.023

Thanissery, R., Kathariou, S., and Smith, D. P. (2014). Rosemary oil, clove oil, and a mix of thyme-orange essential oils inhibit Salmonella and Campylobacter in vitro. J. Appl. Poult. Res. 23, 221-227. doi: 10.3382/japr.201300888

Thanissery, R., and Smith, D. P. (2014). Marinade with thyme and orange oils reduces Salmonella Enteritidis and Campylobacter coli on inoculated broiler breast fillets and whole wings. Poult. Sci. 93, 1258-1262. doi: 10.3382/ps.201303697

Thibodeau, A., Fravalo, P., Gauthier, R., Guévremont, E., Bergeron, N., LaurentLewandowski, S., et al. (2014). Modification of Campylobacter jejuni broiler colonization by a feed additive composed of encapsulated organic acids and essential oils. J. Agric. Sci. Technol. A 4, 853-864.

Thibodeau, A., Fravalo, P., Yergeau, É., Arsenault, J., Lahaye, L., and Letellier, A. (2015). Chicken caecal microbiome modifications induced by Campylobacter jejuni colonization and by a non-antibiotic feed additive. PLoS One 10:e0131978. doi: 10.1371/journal.pone.0131978 
Thomas, M. T., Shepherd, M., Poole, R. K., van Vliet, A. H., Kelly, D. J., and Pearson, B. M. (2011). Two respiratory enzyme systems in Campylobacter jejuni NCTC 11168 contribute to growth on L-lactate. Environ. Microbiol. 13, 48-61. doi: 10.1111/j.1462-2920.2010.02307.x

Tiihonen, K., Kettunen, H., Bento, M. H. L., Saarinen, M., Lahtinen, S., Ouwehand, A. C., et al. (2010). The effect of feeding essential oils on broiler performance and gut microbiota. Br. Poult. Sci. 51, 381-392. doi: 10.1080/00071668.2010. 496446

Troxell, B., Petri, N., Daron, C., Pereira, R., Mendoza, M., Hassan, H. M., et al. (2015). Poultry body temperature contributes to invasion control through reduced expression of Salmonella pathogenicity island 1 genes in Salmonella enterica serovars Typhimurium and Enteritidis. Appl. Environ. Microbiol. 81, 8192-8201. doi: 10.1128/AEM.02622-15

Tschech, A., and Schink, B. (1985). Fermentative degradation of resorcinol and resorcylic acids. Arch. Microbiol. 143, 52-59. doi: 10.1007/bf00414768

Tsuneki, H., Ma, E. L., Kobayashi, S., Sekizaki, N., Maekawa, K., Sasaoka, T., et al. (2005). Antiangiogenic activity of $\beta$-eudesmol in vitro and in vivo. Eur. J. Pharmocol. 512, 105-115.

Tu, Q. V., McGuckin, M. A., and Mendz, G. L. (2008). Campylobacter jejuni response to human mucin MUC2: modulation of colonization and pathogenicity determinants. J. Med. Microbiol. 57, 795-802. doi: 10.1099/jmm. $0.47752-0$

Turnberg, L. A. (1987). Gastric mucus, bicarbonate and $\mathrm{pH}$ gradients in mucosal protection. Clin. Invest. Med. 10, 178-180.

Turner, J. R. (2009). Intestinal mucosal barrier function in health and disease. Nat. Rev. Immunol. 9, 799-809. doi: 10.1038/nri2653

U.S Food and Drug Administration [FDA] (2018). GRAS Substances (SCOGS) Database.

Ultee, A., Bennik, M. H. J., and Moezelaar, R. (2002). The phenolic hydroxyl group of carvacrol is essential for action against the food-borne pathogen Bacillus cereus. Appl. Environ. Microbiol. 68, 1561-1568. doi: 10.1128/aem.68.4.15611568.2002

Umaraw, P., Prajapati, A., Verma, A. K., Pathak, V., and Singh, V. P. (2017). Control of Campylobacter in poultry industry from farm to poultry processing unit: a review. Crit. Rev. Food Sci. Nutr. 57, 659-665. doi: 10.1080/10408398. 2014.935847

Upadhyay, A., Arsi, K., Wagle, B. R., Upadhyaya, I., Shrestha, S., Donoghue, A. M., et al. (2017). Trans-cinnamaldehyde, carvacrol, and eugenol reduce Campylobacter jejuni colonization factors and expression of virulence genes in vitro. Front. Microbiol. 8:713. doi: 10.3389/fmicb.2017. 00713

van der Aar, P. J., Fahey, G. C. Jr., Ricke, S. C., Allen, S. E., and Berger, L. L. (1983). Effects of dietary fibers on mineral status of chicks. J. Nutr. 113, 653-661. doi: $10.1093 /$ jn/113.3.653

van der Wielen, P. W., Biesterveld, S., Notermans, S., Hofstra, H., Urlings, B. A., and van Knapen, F. (2000). Role of volatile fatty acids in development of the cecal microflora in broiler chickens during growth. Appl. Environ. Microbiol. 66, 2536-2540. doi: 10.1128/aem.66.6.2536-2540.2000

Van Deun, K., Haesebrouck, F., Van Immerseel, F., Ducatelle, R., and Pasmans, F. (2008). Short-chain fatty acids and L-lactate as feed additives to control Campylobacter jejuni infections in broilers. Avian Pathol. 37, 379-383. doi: 10.1080/03079450802216603

Van Immerseel, F., Fievez, V., De Buck, J., Pasmans, F., Martel, A., Haesebrouck, F., et al. (2004). Microencapsulated short-chain fatty acids in feed modify colonization and invasion early after infection with Salmonella Enteritidis in young chickens. Poult. Sci. 83, 69-74. doi: 10.1093/ps/ 83.1.69

Vandamme, P., Dewhirst, F. E., Paster, B. J., and On, S. L. W. (2006). Bergey's Manual of Systematic Bacteriology: The Proteobacteria (Part C), 2nd Edn, Vol. 2, eds G. Garrity, D. J. Brenner, J. T. Staley, N. R. Krieg, D. R. Boone, P. DeVos, et al. (Berlin: Springer Science \& Business Media), 1147-1160.

Vegge, C. S., Brøndsted, L., Li, Y. P., Bang, D. D., and Ingmer, H. (2009). Energy taxis drives Campylobacter jejuni toward the most favorable conditions for growth. Appl. Environ. Mmicrobiol. 75, 5308-5314. doi: 10.1128/AEM.00 287-09

Velayudhan, J., Jones, M. A., Barrow, P. A., and Kelly, D. J. (2004). Lserine catabolism via an oxygen-labile L-serine dehydratase is essential for colonization of the avian gut by Campylobacter jejuni. Infect. Immun. 72, 260-268. doi: 10.1128/iai.72.1.260-268.2004

Velayudhan, J., and Kelly, D. J. (2002). Analysis of gluconeogenic and anaplerotic enzymes in Campylobacter jejuni: an essential role for phosphoenolpyruvate carboxykinase. Microbiology 148, 685-694. doi: 10.1099/00221287-1483-685

Vidanarachchi, J. K., Mikkelsen, L. L., Sims, I. M., Iji, P. A., and Choct, H. (2005). Phytobiotics: alternatives to antibiotic growth promoters in monogastric animal feeds. Recent Adv. Anim. Nutr. 15, 131-144.

Villemur, R. (1995). Coenzyme A ligases involved in anaerobic biodegradation of aromatic compounds. Can. J. Microbiol. 41, 855-861. doi: 10.1139/ m95-118

Wallace, R. B. (2003). "Campylobacter," in Foodborne Microorganisms of Public Health Significance, 6th Edn, ed. A. D. Hocking (Sydney: Australian Institute of Food Science and Technology), 311-331.

Wang, G., Clark, C. G., Taylor, T. M., Pucknell, C., Barton, C., Price, L., et al. (2002). Colony multiplex PCR assay for identification and differentiation of Campylobacter jejuni, C. coli, C. lari, C. upsaliensis, and C. fetus subsp. fetus. J. Clin. Microbiol. 40, 4744-4747.

Wang, X., Farnell, Y. Z., Peebles, E. D., Kiess, A. S., Wamsley, K. G. S., and Zhai, W. (2016). Effects of prebiotics, probiotics, and their combination on growth performance, small intestine morphology, and resident Lactobacillus of male broilers. Poult. Sci. 95, 1332-1340. doi: 10.3382/ps/pew030

Wang, Y. H., Avula, B., Nanayakkara, N. D., Zhao, J., and Khan, I. A. (2013). Cassia cinnamon as a source of coumarin in cinnamon-flavored food and food supplements in the United States. J. Agric. Food Chem. 61, 4470-4476. doi: $10.1021 /$ jf 4005862

Wei, A., and Shibamoto, T. (2007). Antioxidant activities and volatile constituents of various essential oils. J. Agric. Food Chem. 55, 1737-1742. doi: 10.1021/ jf062959x

Wei, S., Morrison, M., and Yu, Z. (2013). Bacterial census of poultry intestinal microbiome. Poult. Sci. 92, 671-683. doi: 10.3382/ps.2012-02822

Wenk, C. (2003). Herbs and botanicals as feed additive in monogastric animals. Asian Australas. J. Anim. Sci. 16, 282-289. doi: 10.5713/ajas.2003.282

White, P. L., Baker, A. R., and James, W. O. (1997). Strategies to control Salmonella and Campylobacter in raw poultry products. Sci. Tech. 16, 525-541. doi: 10. 20506/rst.16.2.1046

Wilkinson, N., Hughes, R. J., Aspden, W. J., Chapman, J., Moore, R. J., and Stanley, D. (2016). The gastrointestinal tract microbiota of the Japanese quail, Coturnix japonica. Appl. Microbiol. Biotechnol. 100, 4201-4209. doi: 10.1007/s00253-015$7280-\mathrm{z}$

Williams, P., and Losa, R. (2001). The use of essential oils and their compounds in poultry nutrition. Worlds Poult. Sci. J. 17, 14-15.

Windisch, W., and Kroismayr, A. (2006). The Effects of Phytobiotics on Performance and Gut Function in Monogastrics. Cape Town: World Nutrition Forum, 85-90.

Windisch, W., and Kroismayr, A. (2007). Natural phytobiotics for health of young piglets and poultry: mechanisms and application. Poult. Sci. 86:643.

Woodward, C. L., Kwon, Y. M., Kubena, L. F., Byrd, J. A., Moore, R. W., Nisbet, D. J., et al. (2005). Reduction of Salmonella enterica serovar Enteritidis colonization and invasion by an alfalfa diet during molt in Leghorn hens. Poult. Sci. 84, 185-193. doi: 10.1093/ps/84.2.185

World Health Organization [WHO] (2013). The Global View of Campylobacteriosis: Report of an Expert Consultation. Utrecht: World Health Organization.

Wright, J. A., Grant, A. J., Hurd, D., Harrison, M., Guccione, E. J., Kelly, D. J., et al. (2009). Metabolite and transcriptome analysis of Campylobacter jejuni in vitro growth reveals a stationary-phase physiological switch. Microbiology 155, 80-94. doi: 10.1099/mic.0.021790-0

Xu, J., Zhou, F., Ji, B. P., Pei, R. S., and Xu, N. (2008). The antibacterial mechanism of carvacrol and thymol against Escherichia coli. Lett. Appl. Microbiol. 47, 174-179. doi: 10.1111/j.1472-765X.2008.02407.x

Yousaf, M. S., Ahmad, I., Ashraf, K., Rashid, M. A., Hafeez, A., Ahmad, A., et al. (2017). Comparative effects of different dietary concentrations of $\beta$-galacto-oligosaccharides on serum biochemical metabolites, selected caecel microbiota and immune response in broilers. J. Anim. Plant Sci. 27, 98-105.

Zemek, J., Košíková, B., Augustin, J., and Joniak, D. (1979). Antibiotic properties of lignin components. Folia Microbiol. 24, 483-486. doi: 10.1007/bf02927180 
Ziprin, R. L., Young, C. R., Stanker, L. H., Hume, M. E., and Konkel, M. E. (1999). The absence of cecal colonization of chicks by a mutant of Campylobacter jejuni not expressing bacterial fibronectin-binding protein. Avian Dis. 43, 586-589.

Zoetendal, E. G., Collier, C. T., Koike, S., Mackie, R. I., and Gaskins, H. R. (2004). Molecular ecological analysis of the gastrointestinal microbiota: a review. J. Nutr. 134, 465-472. doi: 10.1093/jn/134.2.465

Zviely, M. (2004). "Aromatic chemicals," in Kirk-Othmer Encyclopedia of Chemical Technology, 5th Edn, ed. A. Seidel (New York, NY: Wiley Interscience), $226-262$.
Conflict of Interest Statement: The authors declare that the research was conducted in the absence of any commercial or financial relationships that could be construed as a potential conflict of interest.

Copyright $\odot 2019$ Micciche, Rothrock, Yang and Ricke. This is an open-access article distributed under the terms of the Creative Commons Attribution License (CC BY). The use, distribution or reproduction in other forums is permitted, provided the original author(s) and the copyright owner(s) are credited and that the original publication in this journal is cited, in accordance with accepted academic practice. No use, distribution or reproduction is permitted which does not comply with these terms. 